\title{
Hurricane Camille 1969 and Storm-Triggered Landslides in the Appalachians and a Perspective in a Warmer Climate
}

\author{
Diandong Ren \\ Department of Imaging and Applied Physics, Curtin University of Technology, Perth, Australia \\ Email: Diandong.Ren@curtin.edu.au, rendianyun@gmail.com
}

Received 8 December 2015; accepted 26 January 2016; published 29 January 2016

Copyright (C) 2016 by author and Scientific Research Publishing Inc. This work is licensed under the Creative Commons Attribution International License (CC BY). http://creativecommons.org/licenses/by/4.0/

(c) ()

\section{Abstract}

This study analyzes storm-triggered landslides in the US Appalachians, in the current geological setting. Concave valleys that favor the convergence of surface runoff are the primary locales for landslides. If the slopes are weathered to the same degree and have the same vegetation coverage, slope orientation (azimuthal) is not critical for slope stability. However, it is found that for the region south of the Black Mountains (North Carolina), north-facing slopes are more prone to slide, because, for the regions not limited by water availability (annual precipitation), the northern slopes usually are grass slopes. For the slopes of the Blue Ridge Mountains, south facing slopes are more prone to slide. Gravity measurements over the past decade reveal that geological conditions, the chute system and underground cracks over the region are stable. Future changes in stormtriggered landslide frequency are primarily controlled by changes in extreme precipitation. Thus, a series of ensemble climate model experiments is carried out to investigate possible changes in future extreme precipitation events, using a weather model forced by atmospheric perturbations from ensemble climate models. Over 50 locations are identified as prone to future landslides. Many of these locales are natural habitats to the Appalachian salamanders. In a future warmer climate, more severe extreme precipitation events are projected because of increased atmospheric water vapor and more frequent passages of tropical cyclone remnants. There is also a likely shift of tropical cyclone tracks and associated extreme precipitations, and the cluster center of Appalachians's scarps is expected to move westward, with ecological consequences for the endemic salamanders.

\section{Keywords}

Extreme Precipitation, Climate Change, Landslides, Flash Floods, Endemic Salamanders to Appalachians, Ecosystem in Mountains, Tropical Cyclone Remnants and Extra-Tropical Transition, 


\section{Introduction}

The $5^{\text {th }}$ assessment report of the Intergovernmental Panel on Climate Change (Chapter 7 in Working Group 1 Report of [1]) anticipated increased occurrence frequency of extreme events and the assertions seem agree with recent unfolds from Mother Nature: Last year (2014) several high-temperature records were broken in Europe, a spectacular heat wave struck Australia, and the California entered a fourth year of exceptional drought, while the memory of the destructive Hurricane Sandy (2012, the Atlantic basin) and Typhoon Haiyan (2013, the North West Pacific basin) still fresh. Such extremes may have devastating consequences on societies, lifestyles and infrastructures. This study focuses on storm-triggered landslides/debris flows over the US Appalachians, a common form of natural hazards associated with extreme precipitation. The landslide-prone regions are identifiable from the geological, geographical, and extreme precipitation characteristics of the region, using an extensively tested numerical modeling system, referred to as SEGMENT-Landslide [2]-[6].

One of the focus regions is the central Virginia Blue Ridge Mountains area, Nelson County, which in 1969 experienced slope failure as a result of extreme precipitation from Hurricane Camille remnant that recharged the area's hill-slope soil. The Blue Ridge Mountains have a long landslide history (R. Pielke Sr., personal communication 2012). There is little dispute about the causal factors of the 1969 slides [7] [8]. Because the 1969 landslides produced significant life and economic loss, it is of great practical importance to investigate the probability of future such events. Climate warming is commonly seen as the likely major cause, by contributing to the severity of rainstorms (Chapter 14 in [1]). Alternatively, it is suggested that another important contributor is increased exposure, due to the expanding of population into naturally unstable areas, thereby disturbing the primitive land cover and land use.

Another focus region is Macon County, North Carolina where landslide hazard mapping has been completed by USGS (www.gwology.enr.state.nc.us). These maps are very helpful for studying potential and known landslide hazards. The Black Mountain Range (Buncombe County) is identified by SEGMENT-Landslide as another unstable region that, as yet, is not mapped. This region satisfies the confluence of surface runoff and graded sloping that makes it highly prone to the progressive bulking debris flows ([9] and Figure S1). SEGMENTLandslide also provides the ability to examine vegetation effects on slope stability.

Here, a SEGMENT-Landslide case study of the August 1969 Camille (Figure 1) is undertaken using atmospheric parameters reproduced from the Advanced Research version of the Weather Research and Forecasting model (ARW-WRF or, simply, WRF [10]). Camille occurred in a pre-satellite era, so it is only possible to verify the reconstructed heavy rainfall event with eye witness accounts and indirect observations such as drawn birds, and the extremely rapidly increasing water levels in the creeks. The model simulated dynamic and thermodynamic features form the basis for a series of experiments on climate sensitivity using the hypothesis of [11]. As the climate warms, extreme precipitation events are likely to become more common [12], and future return frequencies of such events therefore must be estimated and included in the forcing of the landslide model.

What makes storm-triggered landslides complicated are many factors that balance each other, such as localized disturbances that enhance instability of weathered regolith (e.g., extracting and recharging of ground water); reducing root reinforcement (e.g., wild fires or over-grazing); and sporadic celestial or geologiocal impacts (e.g., earthquakes and volcanic eruptions). Many factors defy direct measurements. The region of interest includes both Nelson County and the surrounding areas affected by significant Karst development. Remotely sensed observations (e.g., the Gravity Recovery and Climate Experiment, GRACE [6] satellite) over the past decade has provided an opportunity to examine the bedrock cracking conditions over the Appalachians.

The region of interest lies in the conjuncture of low level jets and Atlantic basin hurricanes. Climate change will impact the Appalachian region's vulnerability to extreme precipitation and storm-triggered landslides. The modeling approach in this study extracts information from historical landslide cases (e.g., lesson learned from the 1969 hurricane Camille case). The prediction of future landslide events by SEGMENT-Landslide, driven by atmospheric parameters provided by climate models, provides additional information for hazard mitigation and infrastructure protection. 


\section{Model and Methods}

Landslides involve weathered rock material, referred to as granular material (GM), which spreads across graded mountain slopes (see Appendix I). GM has unique mechanical properties (e.g., viscosity, cohesion, and dry repose angle/frictional angle). Effects from moisture content, vegetation roots, and external loading from earthquakes, canopy wind loading, or direct impact of storm raindrops all need to be considered in the context of granular material. Because there are many cancelling effects, or many factors that balance each other, that make it difficult to draw definitive conclusions on the net effects of soil, vegetation, and precipitation characteristics on slope stability, SEGMENT-Landslide, an advanced 3-D numerical model, thus is used to investigate storm-triggered landslides.

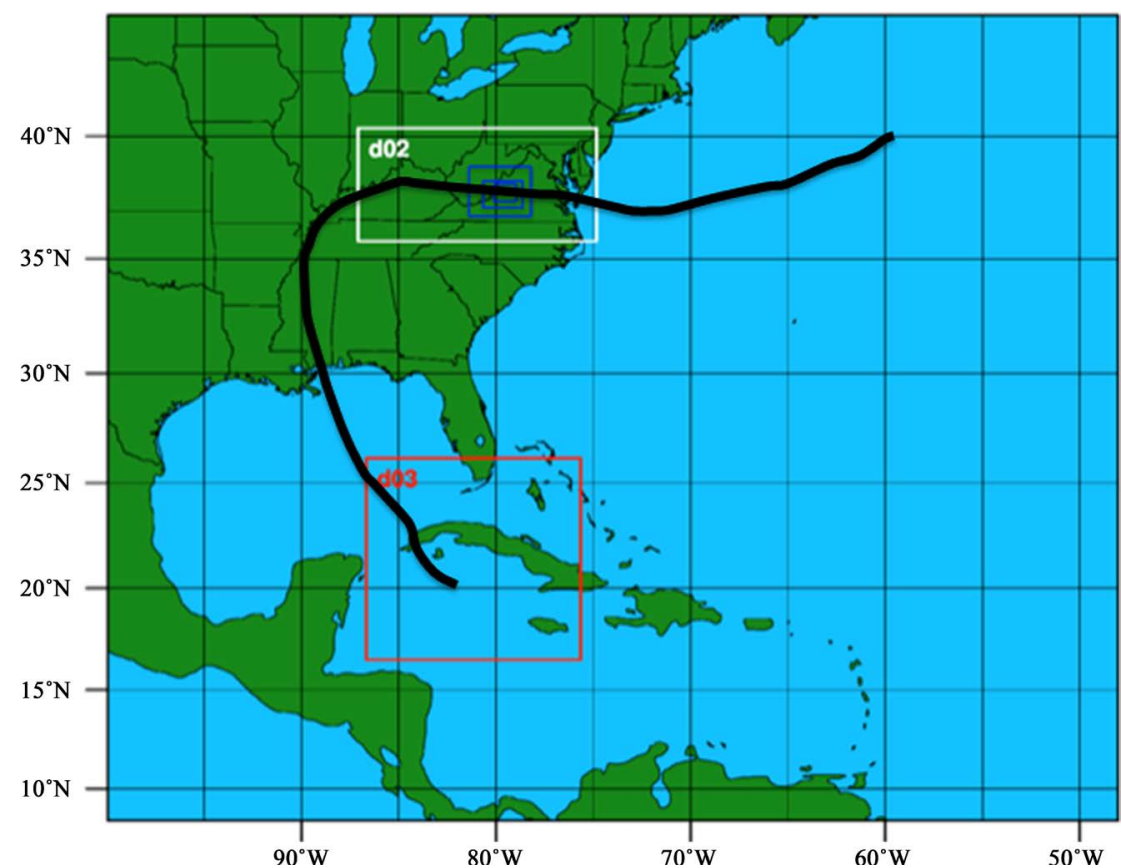

(a)

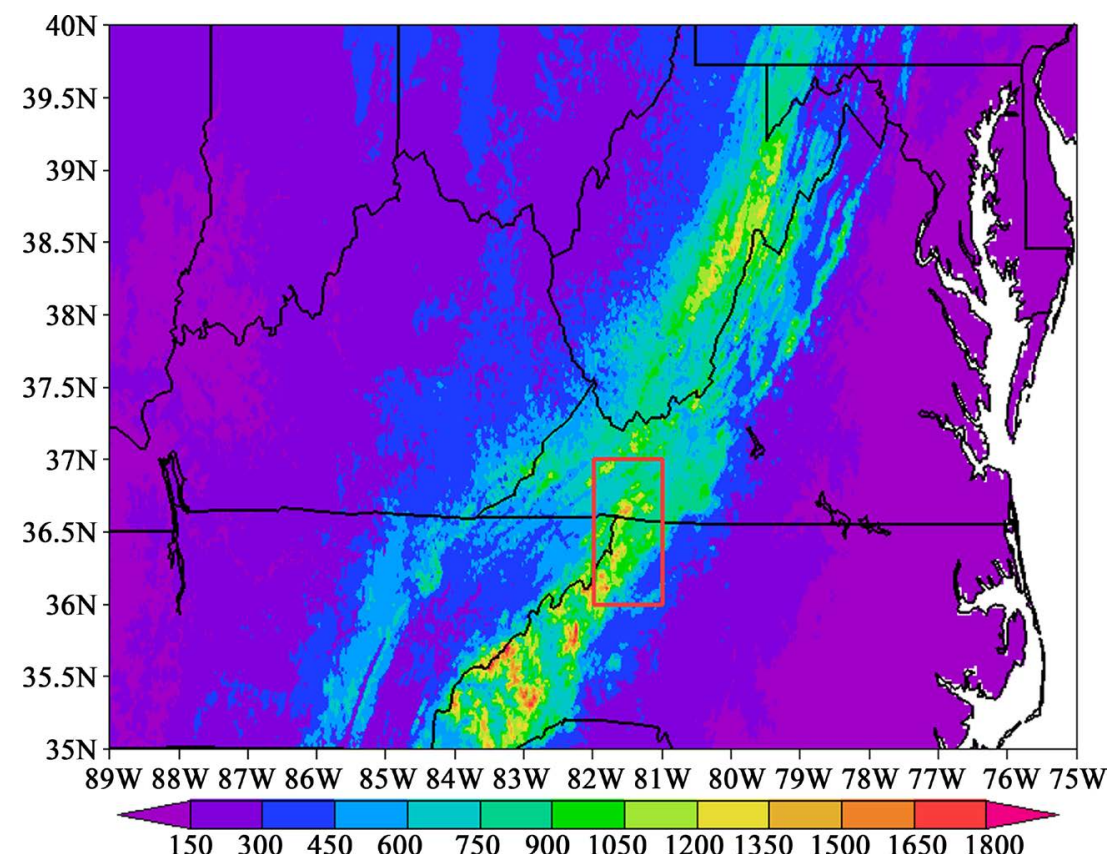

(b) 

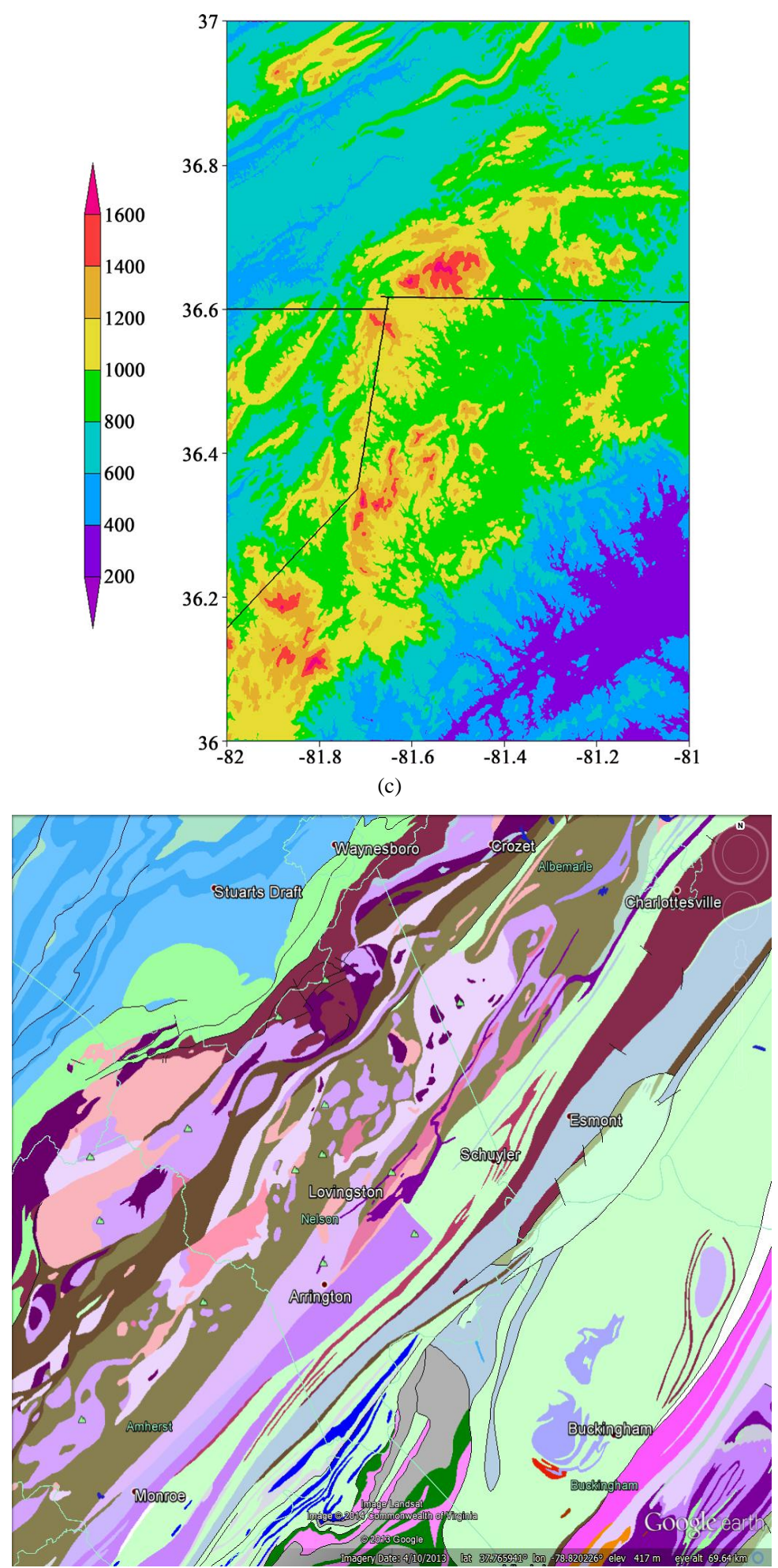

(d)

Figure 1. Panel (a) shows the selected WRF domains and the nested domain. domain 1 is of $27 \mathrm{~km}$ resolution. the innermost (domain 5) is of $1 \mathrm{~km}$ resolution. color shadings in panel (b) are the shaded relief images of the 9-km digital elevation map in domain 3. Panel (c) is the 30-m DEM in the blue ridge region (defined by the red box in (b)). SEGMENT-landslide actual runs on this resolution of DEM. Panel (d) is the geological map of blue ridge mountains. Source: Google earth. Dr. Kongyan Zhu assisted in obtaining this map. 


\subsection{Model}

The SEGMENT-Landslide [2]-[6], a process-based landslide modeling system that has been used in a wide range of storm-triggered landslide studies, is used here to investigate historical debris flows in Nelson County on August 19-20, 1969, particularly the cause and possible future preventative and mitigation actions. The atmospheric parameters as input to SEGMENT-Landslide are provided by atmospheric models.

In this study, WRF (version 3.5, Eulerian mass coordinate) is used to reproduce the historical 1969 Camille precipitation and to project changes in similar events under future climate scenarios. WRF is a fully compressible non-hydrostatic, primitive-equation model with multiple-nesting capabilities to enhance resolution over areas of interest. Over Nelson County, five nested domains are configured as shown in Figure 1(a). Domain 1 is the coarsest mesh and has 501 by 462 grid-points in the north-south and east-west directions, respectively, with a horizontal grid spacing of $27 \mathrm{~km}$. This configuration comfortably covers the region tracked by Camille during its entire life cycle. During our 10-day simulation, boundary condition setting is important because the spurious calculation waves bounced back into the simulation domain [13]. Radiative boundary conditions are used to minimize the impact of domain size and boundary conditions. Domain 2 covers the Blue Ridge is nested with 400 $\times 380$ grid points. Domain 3 is parallel to Domain 2 but with $720 \times 600$ gridpoints at $9 \mathrm{~km}$ grid spacing. This domain covers the oceanic period of Camille's life cycle. To facilitate providing precipitation information to SEGMENT (which runs on $30 \mathrm{~m}$ resolution DEM/topography), two further nested domains (Domains 4 and 5) were employed within Domain 2, with nesting ration of 3 in cascading, producing grid spacing of $3 \mathrm{~km}$ and 1 $\mathrm{km}$, respectively.

Running WRF for the hurricane Camille raises an important technical issue, namely, the lack of sea surface temperatures (SSTs) information in the reanalysis data back to 1969. Tropical cyclones (TCs) are highly sensitive to SSTs, as shown in [10]. For this historical case, which occurred prior to the remote sensing era, the Hadley Centre Global Sea Ice and Sea Surface Temperature (HadISST V1.1) is used, and is interpolated to daily intervals from monthly means. Similarly, all the simulations used the same initial and boundary conditions, derived from the 2.5-degree coarse resolution NCEP/NCAR reanalyses rather than the 1-degree FNL analyses, which starts well-after 1969. The NNRP Variable Table is used in the pre-processing stage of WRF. The analyses are interpolated to the WRF-model grid to provide the initial conditions for 00UTC 14 August 1969, as well as 6-hourly lateral boundary conditions for the 27-km outermost domain. Domains 1 - 3 all start from 00UTC 14 Aug 1969. Domains 4 and 5 starts two days later to provide sufficient time for model spin-up. This model configuration is referred to as the control-run (CNTRL). WRF run is initialized at 00UTC on 14 August 1969 and integrated ten days until 00 UTC on 24 August 1969. The model's initial and lateral conditions are taken from the NCEP reanalyses with the outermost lateral boundary conditions updated every 6 hours, and the SST conditions updated daily.

\subsection{Method}

As described in Appendix of [6], SEGMENT-Landslide is a fully three-dimensional, dynamical landslide model that incorporates the interactions of various causal factors: mechanical properties of the granular sliding material (dry or wet), hydrologic cycles and the imposed stress mfields; the hydrological and mechanical effects of vegetation on storm-triggered landslides; and the fatigue of bedrock (development of the crevasses). The model requires a wide range of input variables such as land cover, land use and geological data, all of which were provided for this research by the University of Oklahoma group. The digital elevation data (DEMs) were obtained from the the Advanced Spaceborne Thermal Emission and Reflection Radiometer (ASTER) Global Digital Elevation Model Version 2 (GDEM V2), released on October 17, $2011(1 \times 1$ degree tiles available at https://asterweb.jpl.nasa.gov/gdem.asp), at $\sim 30 \mathrm{~m}$ resolution (Figure 1(b), Figure 1(c)). A quality control procedure is applied to fill in the missing values in the ASTER GDEM. For Macon County (NC), there are DEMs available at $\sim 6 \mathrm{~m}$ horizontal resolution (color shading of Figure 2). To reproduce historical landslide development, precipitation forcing was obtained from WRF in a one-way nested mode with the inner-most domain having a horizontal resolution of $1 \mathrm{~km}$. Even there are $6 \mathrm{~m}$ DEMs over the Macon County, SEGMENT-Landslide still uses the $1 \mathrm{~km}$ precipitation from WRF (i.e., no further downscaling is performed). The multiple-level nesting approach circumvented the necessity for dynamic or empirical downscaling procedures, in order to match the resolutions of model precipitation and topography. Taking the forecasting experience of Hurricane Sandy (2012), the cumulus parameterization scheme for the outer domains I-III selects the Tiedtke scheme [14]. The 
inner domains use explicit physics.

For simulating future (years 2060-2080) storm-triggered landslides, the WRF model is used in the same "pseudo-global warming" approach proposed by [11]. The method had been detailed in [6] and here only the improved aspects are presented. To quantify the projected thermodynamic changes due to increased anthropogenic greenhouse gases, an ensemble of twelve IPCC Fourth Assessment Report (AR4) general circulation model (GCM) simulations of monthly temperature, SST and mixing ratio values, under the SRES A1B scenario are used (Table 1). A two-decade average temperature change was then computed from the August monthly (as

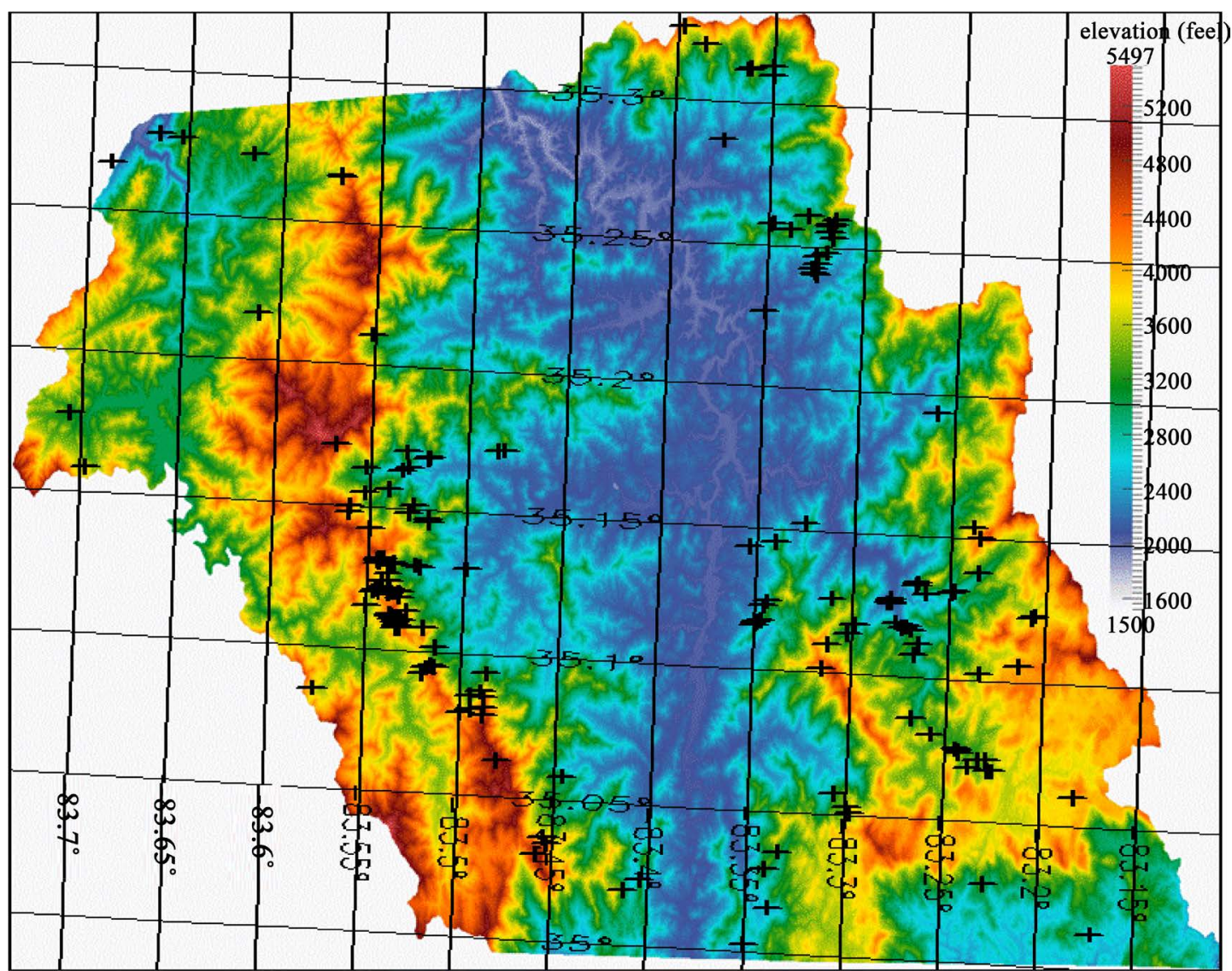

Figure 2. The SEGMENT-landslide simulation of the macon county area under a $35 \mathrm{~mm}$ uniform precipitation when soil moisture is set at annual mean values. the cross marks indicate the landslide prone areas.

Table 1. The climate model used in this study.

\begin{tabular}{ccc}
\hline Model Name & Institution & Horizontal resolution \\
\hline CNRM-CM5 & Centre National de Recherches Meteorologiques & $256 \times 128$ \\
CCSM4 & National Center for Atmospheric Research & $288 \times 192$ \\
CSIRO-Mk3.6.0 & Commonwealth Scientific and Industrial Research Organization & $192 \times 96$ \\
GFDL-CM3 & Geophysical Fluid Dynamics Laboratory & $144 \times 90$ \\
BCC-CSM1.1 & Beijing Climate Center, China Meteorological Administration & $128 \times 64$ \\
CanESM2 & Canadian Center for Climate Modelling and Analysis & $128 \times 64$ \\
FGOALS-g2 & Institute of Atmospheric Physics, Chinese Academy of Sciences & $128 \times 60$ \\
IPSL-CMSA-MR & Institute Pierre-Simon Laplace & $144 \times 1143$ \\
MIROC5-hires & Atmosphere and Ocean Research Institute, The Tokyo University & $256 \times 128$ \\
INM-CM3.0 & Institute of Numerical Mathematics, Russian Academy of Science & $72 \times 45$ \\
HadCM3 & The UK MedOffice & $96 \times 73$ \\
ECHAM5 & Max Plank Institute (MPI) & $128 \times 64$ \\
\hline
\end{tabular}


hurricane Camille caused landslides on August $19-20^{\text {th }}$ ) averages from the 12-member GCM ensemble for the periods (1960-80) and (2060-80).

Differences between the 2060s and 1960s decades were computed for each grid cell, and these changes were subsequently added to the original GFS analyses and SSTs, to simulate future Camille-like hurricanes in the (2060-2080) time frame. To resolve the mesoscale evolution of Camille-like event, the WRF domain features a larger outer domain with $27 \mathrm{~km}$ grid spacing, along with a $1 \mathrm{~km}$ resolution nested innermost domain within which SEGMENT-Landslide is actually run. Other WRF parameters are set identical as in [6] [10]. Simulations were initialized at 00 UTC 14, August 1969 and run for 10 days. For the nested domains, the parent domain provides lateral boundary conditions and one-way nesting is used.

\subsection{Extreme Precipitation in a Future Climate}

The present knowledge base of extreme precipitation and its trend in a warmer climate is summarized in the Appendix II. For storm-triggered landslides, extreme precipitation can be either a severe storm (high precipitation rate) lasting several hours, or can be a moderate rain rate lasting several consecutive days. In estimating the return frequency of extreme precipitation from climate model simulations, the definition of extreme precipitation in [4] is followed. For individual extreme precipitation events such as that of Camille 1969 over Nelson County and future occurrences, the precipitation pattern will be compared with its historical precedent. Because hurricanes play such important roles in this region's extreme precipitation events, future changes in hurricanes that follow a similar track as Camille 1969 are investigated in detail. The statistical diagnostic schemes involved are not detailed here and interested readers are referred to [15].

\section{Data}

To account for the stability of slopes, only a surface transport type of model (in geomorphology term), such as SEGMENT-Landslide, is not adequate. Knowledge of the slope's material properties over a sufficiently large neighboring area also is a prerequisite. The following subsections are organized according the triads of stormtriggered landslide prerequisites, namely, geological condition, surface loading and vegetation roots, and extreme precipitation.

\subsection{High Resolution Digital Elevation Maps (DEMs)}

High-resolution elevation data are needed because the ultimate driver for landslides is the uneven surface elevations. There are various sources for high-resolution DEMs. For example, the National Aeronautic and Space Administration (NASA) Shuttle Radar Topography Mission (SRTM [16]) provides DEMs of order $10 \mathrm{~m}$ resolution. Especially for dynamical simulation of landslides, high resolution DEMs can be expected to represent individual slopes, preferably the graded slope feature for extended slopes. On Earth surface, the steepest inclinations that can be represented by a DEM of 6, 60, 90, 900, 5000 and 20,000 m resolution are, respectively, 89.77, 87.71, 86.56, 59.0, 16.7, and 4.3 degree. Thus, it is almost impossible to use DEMs of $1000 \mathrm{~m}$ spatial resolution or coarser to reasonable identify unstable slopes on Earth. The landslides of most concern are in the range 100 $1000 \mathrm{~m}$ in spatial extent. The 30-m ASTER GDEM generally suffices; although it cannot realistically represent the steep upper portion of many extended slopes, which have steep upper regions and gentle toe slopes (Figure S1(b)). For the four surveyed counties in North Carolina, $6 \mathrm{~m}$ resolution InSAR DEMs are available, which enables representation of slopes as high as 85-degree inclination. For example, over Macon county, the $6 \mathrm{~m}$ resolution InSAR DEMs identify the steepest location as 84.73 degree at $\left(83.59385^{\circ} \mathrm{W}, 35.02944^{\circ} \mathrm{N}\right)$, a 1500 meter long natural slope facing east (most parts of the slope are inclined $>45^{\circ}$ ). The scarp drops by $66 \mathrm{~m}$ in just $6 \mathrm{~m}$, forming a cliff. For the InSAR data, a mask is applied to filter out the residential areas and industrial buildings, infra-structure facilities and lakes/ponds.

To better represent the orographic effects on precipitation [17], the default digital elevation map of WRF is replaced with a $1 \mathrm{~km}$ DEMs produced from the $30 \mathrm{~m}$ ASTER GDEM, whereas the SEGMENT-Landslide still runs on the $30 \mathrm{~m}$ DEMs. The soil and vegetation maps also are refined to $1 \mathrm{~km}$ resolution. Various WRF simulation domains thin the DEMs and land surface maps to the corresponding resolutions of the atmospheric components. These are relevant to convective initiation at hurricane landfall, its track and extra-tropical transition (ET [18]), and precipitation distribution at the region of interest. 


\subsection{Bedrock Geology}

Like many other forms of natural hazards, landslides are highly multi-disciplinary. In addition to surface relief, the bedrock chemical components, foliage and fabric conditions all are critical for slope stability. The surface soil and granular debris arise primarily from the weathering of bedrock, whereas the component advected from remote sites by runoff or Aeolian processes are minor. If the bedrock contains graphite, the weathered granular material will possess viscosity several orders of magnitude smaller than material not containing these components. The scarp size and orientation of debris flows are co-controlled by chute density and its distribution, and the precipitation morphology. In general, anticlinorium ridges in fault zones containing mesoproterozoic crystalline rocks (e.g., biotite augen gneiss, granulite, amphibolite, anorthosite, granite, granodiorite, charnockite, etc.) in its core and flanked by younger gneiss are locations prone to sliding. The rock units with massive or poorly developed in biotite foliation usually are stable bedrocks. Rock units with a biotite or amphibole foliations (especially larger specks on the cross-sectional surface when broken) and/or gneiss textures are highly susceptible to sliding. Not only do the crops along the Blue Ridge Mountains satisfy the required geological conditions, all hills are weathered sufficiently and have plenty of sliding material.

Nelson County is located in the Blue Ridge province, which is a rugged area in central Virginia. As shown in Figure 1(c), the Blue Ridge province is an anticlinorium containing Mesoproterozoic crystalline rocks (biotite augen gneiss, granulite, amphibolite, anorthosite, granite, granodiorite, charnockite, etc.) in its core [19]. During its evolution the Blue Ridge province thrusted northwestward over the Paleozoic carbonate rocks of Valley and Ridge and was additionally thrusted by the Piedmont province in the southeast [20]. Mapped mylonites, anastomosing around lenses of less-deformed or undeformed rocks, represent fault zones with multiple movements [19]. In the study region, it is shown that the rock units with a moderate to low susceptibility are massive or poorly developed in biotite foliation. Those with a high susceptibility generally have a biotite or amphibole foliations and/or gneissic textures [8].

\subsection{GRACE Measurements}

The bedrock crevasses are both pathways and 'containers' for fossil ground water. The groundwater changes are measurable by the gravitational field response from Earth orbiting satellites [21]. It is convenient to discuss the global land water cycle from a net precipitation (precipitation minus evaporation) approach, which usually has river runoff flowing back to oceans to close the hydrologic cycle. However, a small fraction also seeps through the soil and bedrock layers to recharge groundwater aquifers. As bedrock cracks open wider, more runoff will be diverted into drainage percolation and saved in groundwater reservoirs (Equation (1) in [22]). Because the surface runoff to the ocean has a turnover time scale of less than a week, this increased replenishment of groundwater is accompanied by local mass variations detectable by gravity-sensitive satellites such as the GRACE [23]. Aside from net precipitation and drainage, other factors also may cause perturbations on the regional gravitational field, for example, irrigation projects [22] and large-scale population and animal migrations. The region of interest has not been affected by these factors over the past several decades. The same precipitation total can mobilize very different amounts of sliding material, as indicated in Figure S2. The density of macroscopic crevasses (an indicator of the bedrock's degree of fracture) is critical in partitioning the precipitation. However, as a rhizosphere layer generally overlies these cracks, there is no simple means for direct measurements of bedrock crevasses/cracks. Fortunately the present remote sensing capability provides an opportunity to indirectly deduce the bedrock-fracturing situation in the region of interest.

\subsection{Soil and Vegetation Conditions}

For storm-triggered landslides, an ideal soil classification scheme should classify soils such that their hydro-mechanical properties are similar within a given classification. A number of soil classification systems are available, depending on the utilizing disciplines and their general engineering or scientific objectives. Some of the most widely used classification systems in the United States are from the US. Department of Agriculture (USDA [24]), International [25], Unified Soil Classification System (USCS [26]), and the American Association of State Highway and Transportation Organization (AASHTO [27]). The commonality among these systems is the use of soil particle sizes in dividing soils into different categories of clay, silt, sand, gravel and large-sized materials, although the boundaries for each of these systems differ (see [28] for more details). This study uses 
the USDA classification system. Soil chemical composition also is important for their hydro-mechanical properties. Unfortunately, none of the four classifications are based on soil chemical compositions. In setting spatially variable soil mechanical properties, not only was the USDA soil map used, but reference also was made to the STATSGO soil data catalogue for its wealth of vertical profile information (Figure S3). The general ranges of soil mechanical properties are listed in Table 5.3 of [5].

The soil mechanical properties are used to parameterize the granular viscosity of the sliding material according to a formula provided in [5]. The setting of the bedrock mechanical properties always references the published geological map of the region of interest. However, care is needed because the documented mechanical strength and viscosity values usually are laboratory-tested results for non-fractured specimens. If there are cracks, the actual values can have orders of magnitude differences. All else being equal (e.g., same lithology, same resting slope, same above ground loading and similar shearing zone depth), scarp sizes of deep-seated, rotational landslides are proportional to the degree of fracture. This, again, is a granular size issue in a more general sense and follows the similar sigmoid curve in its "ensemble" rock size-dependence. In this sense, existing landslide inventories can assist in objectively determining the degree of fracture of the bedrock. If circumstances permit, boreholes should be taken from the sites and the samples tested at the loading pressures they would experience in reality. The mechanical properties obtained in this way should be much more representative than from civil engineering handbooks. In setting up the bedrock mechanical strength, the burying depth, in addition to the geological unit reflecting lithology, should be taken into consideration to reflect the increasing strength of rock with confining pressure. For vegetated surfaces, a parameter $f_{i}$ is introduced to represent the fraction of soil sub-layer ' $i$ ' that is organic matter. The thermal and hydraulic parameters for organic soil are weighted averages of the corresponding mineral soil and those of humus, using an empirical relationship [29].

Compared with the physical properties of hill slopes that affect the potential for landslides, vegetation is far more temporally variable. Choices available for land cover maps are: the USGS National Land Cover Dataset 2001 (NLCD 2001 [30]), the International Geosphere-Biosphere Programme Data and Information System's DISCover (IGBP-DISCover [31]), or the University of Maryland $1 \mathrm{~km}$ land cover maps [32]. Although the latter two are derived from the 1992-1993 Advanced Very High Resolution Radiometer (AVHRR) data (Figure S4), they have slightly different classifications. Fortunately, the differences are primarily around the Polar Regions and do not affect landslide research. In situ archiving of biomass usually is limited to forests with commercial value (e.g. California). In addition to being cost-effective, remote sensing provides the best spatial and temporal coverage of terrestrial biomass. Usually, foliage biomass can be estimated from the Moderate-Resolution Imaging Spectroradiometer (MODIS) leaf area index (LAI) product. Aboveground biomass residing in branches and stems is then derived from generalized, diameter-based allometric methods [3], with reference to a land use map. For example, a unique feature of SEGMENT-Landslide is its treatment of the root properties according to ecosystem functioning, directly based on root mass allocation of vegetation in the residing climate zone. The partitioning of supporting roots, nutrient absorption roots and moisture tapping roots affects soil moisture content and mechanical reinforcement effects. In addition, total biomass loading also is assumed to be proportional to aboveground biomass. To examine the possible mechanisms underpinning the orientation-dependence of Appalachian debris flows, several sensitivity experiments are performed with various vegetation conditions.

As a salient example of the critical role of soil, adding water to sandy soil significantly reduces the ID size (see the Appendix II) and creates a shear surface (the interface between compact, more coherent wet sands and adjacent dry loose sands), thus making the slopes slide-prone. Vegetation effects on slope stability are multifaceted. During the growth season, evapotranspiration and canopy interception of rainfall significantly influence the soil moisture content. Vegetation roots, on the one hand produce a distributed reinforcement web of the soil particles but, on the other hand, facilitate water discharge into deeper depths. A larger volume of sliding material is thus likely being liquefied than would result from a uniform saturation from the surface. In SEGMENTLandslide, these effects are parameterized.

\section{Results}

\subsection{Reproducing the 1969 Camille Precipitation Event}

For reproducing the 19-20 August 1969 debris flows that occurred in Nelson County ( $37.79^{\circ} \mathrm{N}$; $78.88^{\circ} \mathrm{W}$ ), spatially distributed, high-resolution precipitation rates are a prerequisite. Because the region of interest is a southwest-northeast oriented range with large surface elevation gradients (absolute elevations are not that high), pre- 
cipitation is very patchy. In situ measurements typically are unable to identify the "hot spots" (i.e., locations with extreme precipitation and might have debris flow hazards). Remotely sensed precipitation products were not available in 1969. Therefore, nested runs of WRF, with the innermost domain set at $1 \mathrm{~km}$ resolution, currently is the best available alternative.

As shown in Figure 3 (color shading over Domain 3), Camille's rain swath is oriented perpendicular to the Blue Ridge Mountains and is exceedingly narrow. There were east-west assembled rainfall maxima, located respectively on the southeast facing slopes of the Appalachians and the Blue Ridge Mountains. This is a result of upslope flow of vapor. Over Nelson County, there was a perfect alignment of the extreme precipitation triads. The low levels accumulated a thick moisture "pool" because of 1) the higher antecedent soil moisture (the summer of 1969 was wet, and at least four periods of intense rainfall that occurred over this area from May to early August) and thus strong evapotranspiration from vegetation cover; and, more decisively, 2) the remnant vortex of Camille produces low-level water vapor convergence over the region, in a similar manner to a low level jet (LLJ). The vigorous ascent of moist low-level air is from the synergetic lifting of the remnant vortex, a cold front, and the local topography. During 19-20 August, a cold front passed through central Virginia. Thick water vapor collected south of the cold front, and the along slope uplift was the main factor that organized the afore-mentioned heavy precipitation pattern. In the intersection of the Blue Ridge topography and the cold front, moisture was funneled rapidly upward, due to orographic effects. The thunderstorm complex formed, and received a steady, strong moist inflow from the southeast, at low levels. The repeated passage of cloudbursts across Nelson County formed a train of cells sustaining the most intense 6-hour precipitation event on record. Within the thunderstorm complex, each individual storm cell has its own life cycle of maturation, movement away from the mountain range, and dissipation. Then, new cells formed immediately upwind. This genesis region over Nelson County remained locked to the terrain, for many hours. The combination of large-scale atmospheric processes and local topography led to an unprecedented period of heavy rain along the Blue Ridge Mountains.

Primarily because of the severe precipitation, the hills of Nelson County were essentially liquefied. The role of vegetation was then minimized. The chute density and distribution determines the scarp size and sliding material redistribution. The generation of sliding material is partly from surface runoff advection, according to the progressive bulking process described by [9], but primarily through water percolation in crevasses and scouring out a slope material up to a depth greater than for uniform saturation (i.e., destabilizing a large chunk of slope material through increasing pore pressure). Also noteworthy is that the scarps have no preferred azimuthal orientation (Figure 4).

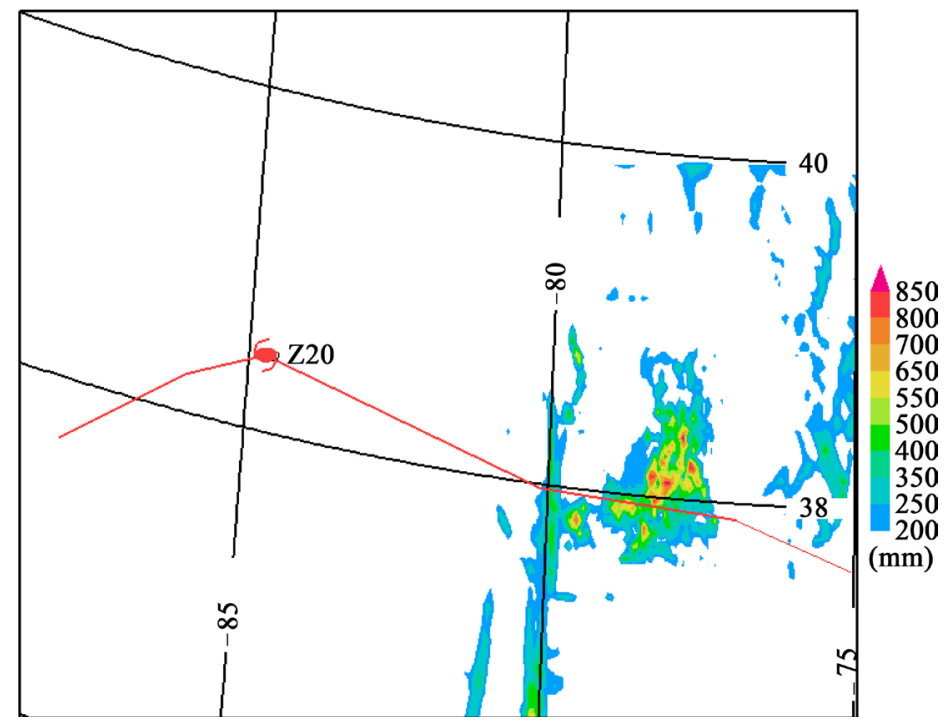

Figure 3. Accumulated precipitation over domain 2 up to 00Z 20 August 1969. The primary precipitation occurred during 19-20 August. WRF captured the apparent orographic effects in the spatial precipitation distribution. The eastern side of the blue ridge mountains received up to $900 \mathrm{~mm}$ of rain in that period. Major precipitation centers are along a line north of the hurricane track and perpendicular to the blue ridge mountains. 


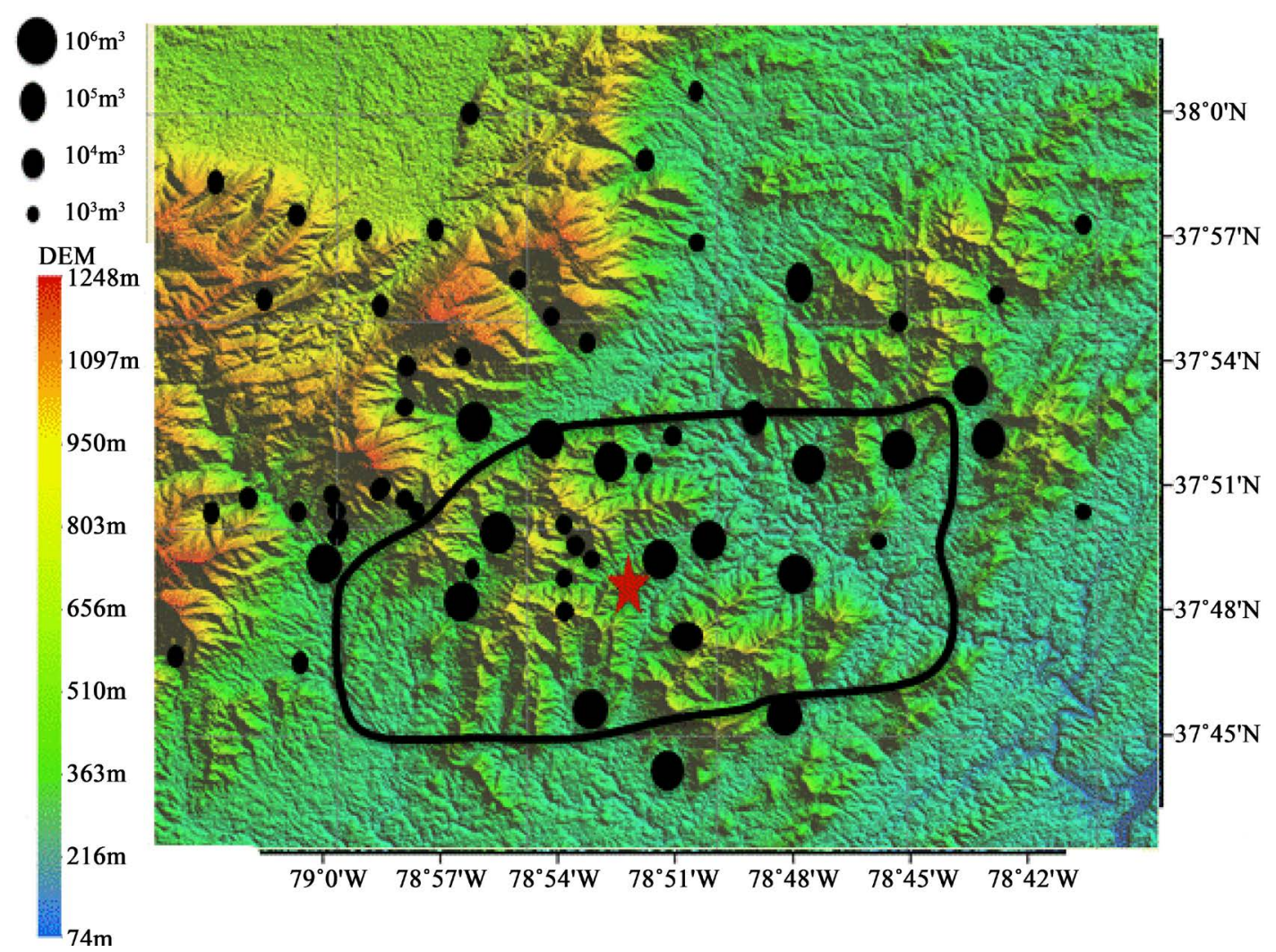

Figure 4. SEGMENT-Landslide simulated landslides after camille 1969. red star is the cluster center of the identified scarps. the sizes of the black dots are proportional to the volume of the involved sliding material. Scarps are still identifiable within the black curve. Drs. Xiyi Shen at OU and frank yu at curtin university helped technically.

Using the high spatial and temporal resolution rain rates of Camille 1969 provided by WRF, Figure 4 shows the SEGMENT-Landslide simulated unstable areas, as indicated by the maximum surface elevation changes larger than 2 meters. The archived observations are generally within the black line defined region. Under the current vegetation regime, the most significant scar is that near Spicewood cabin $\left(37.84^{\circ} \mathrm{N} ;-79.05^{\circ} \mathrm{W}\right)$. This particular sliding event is a characteristic "progressive bulking" type of debris flow [9]. The accumulation area spreads up to $1300 \mathrm{~m}$ elevation, in a fan shape with the fan "handle" extending downslope. The surface runoff essentially is clear water above the $850 \mathrm{~m}$-elevation contour, but at lower elevations it gradually becomes turbid and entrains small stones and coarse granular material into the slide streams. Almost all major valleys that have surface openings $10 \mathrm{~m}$ or wider experienced sliding. Also, landslides know no political borders and there is a scarp right across to the south $\left(37.74^{\circ} \mathrm{N} ; 79.14^{\circ} \mathrm{W}\right)$. Similar scarps are also found for the southeast facing Three Ridge slopes. However, most of the eastern slopes of the Blue Ridge Mountains suffered deep-seated slides, resulted from rainfall percolation to deeper depth along crevasses (the mechanism illustrated in Figure S2) with geological origin. The pattern of the scarps indicates the dual control from precipitation and chute distribution. For example, three southeast facing slopes near the Lesesne State Forest, Massies Mill, VA $\left(37.845^{\circ} \mathrm{N}, 78.98^{\circ} \mathrm{W}\right)$ clearly experienced creek bank failure, whereas the hardest hit slopes, those near Dillard Creek $\left(37.79^{\circ} \mathrm{N}\right.$, $78.89^{\circ} \mathrm{W}$ ), are a mixture of progressive bulking and deep-seated sliding. Wherever the surface topography favors runoff convergence, a greater volume of sliding material will be involved. Within a $\sim 70 \mathrm{~km}^{2}$ region $\left(37.75^{\circ} \mathrm{N}\right.$ $37.85^{\circ} \mathrm{N} ; 78.85^{\circ} \mathrm{W}-78.96^{\circ} \mathrm{W}$ ), the total sliding material involved is about $4.7 \times 10^{6} \mathrm{~m}^{3}$.

While they are critical for major landslides, crevasses underneath the rhizosphere present challenges for in situ surveys to identify, because they are obscured by surface soils and vegetation. These crevasses are the major pathways for recharging groundwater. The proportion of precipitation that is drained into groundwater is closely related to the density of the crevasses. Gravity measurements from GRACE hence can be used to deduce the underground chute condition (Ren 2014b). The area-total annual net primary production (NPP) serves as a smoother for the spatial rainfall heterogeneity and accurately reflects the changes in area total precipitation [33]. 
The annual area total NPP time series may be used as surrogates for precipitation variations over the past decade, to close the dominant term in regional mass balance.

Similar analysis as in Ren [6] is performed with the GRACE measurements (2003-present) over the region of interest $\left(82^{\circ} \mathrm{W}-75^{\circ} \mathrm{W} ; 35^{\circ} \mathrm{N}-41^{\circ} \mathrm{N}\right.$, framed in Figure 5(a)). There are no known consistent human impacts on the gravitational fields over the region in question and the only possible cause of regional mass fluctuation sensed by GRACE is from the groungwater mass changes. The GRACE measurements follow closely the NPP curve (Figure 5(b)), indicating that the portion going to drainage from total precipitation is approximately constant. This is a clear indication of the stability of the chute system. Without external causal factors, such as earthquakes, that might further disintegrate the bedrock over the region, the key reason to remain on alert for possible future natural hazards are impending extreme precipitation events. The past decade is a relatively dry period over the region of interest. The increasing precipitation, and hence the increasing fluids accumulated as groundwater, will make future landslides more severe and more frequent.

Based on the 6-m DEMs over the Macon County (Figure 2), a sensitivity experiment is performed, assuming a uniform 15-cm rainfall in a day precipitation scenario. The cross marks are places that will experience significant mass changes. The USGS surveyed present scarps, primarily those left by hurricane Ivan (Sept. 15-18) and Frances (Sept 5-8, 2004), are a subset of the marked unstable slopes. The slopes that can be represented by the 6-m DEM have no preferred north-orientation components. However, the slopes prone to sliding have an apparent azimuthal preference (Table 2). Over $70 \%$ of the unstable slopes have a north-facing aspect. The most unstable slope segments are those with repose angles between 42 and 66 degrees (for deep seated large scale scarps)

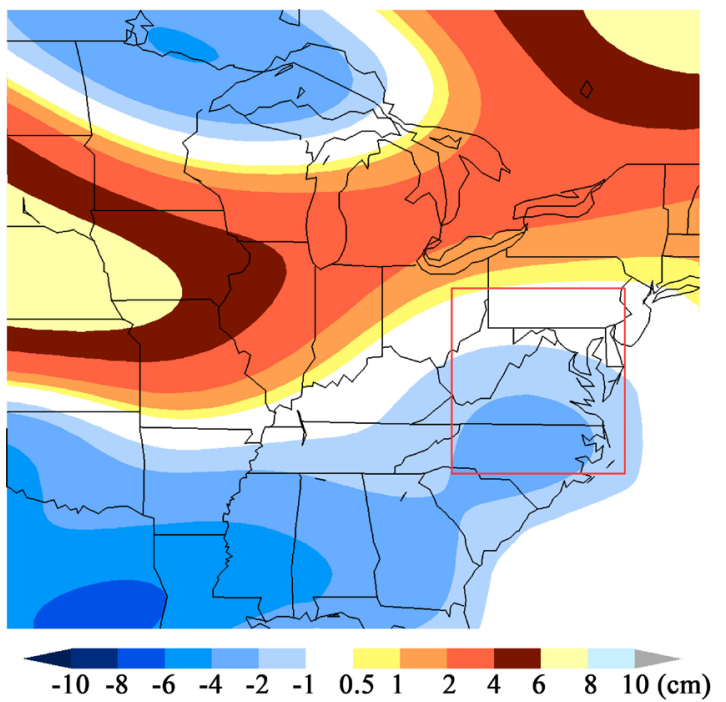

(a)

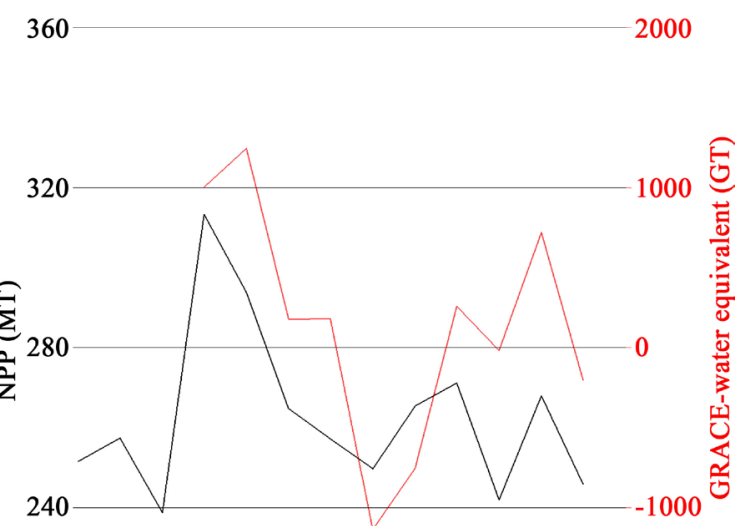

200

(b)

Figure 5. Mass changes from GRACE over the 2003-2013 period. Color shades in (a) is mass loss (blue) and mass gain (red) in water depth equivalent $(\mathrm{cm})$. For convenience, it is subdivided into two 5-yr periods. The differences between the two periods are plotted, that is (2009-2013) minus (2003-2008) values. The spatial resolution is about $100 \mathrm{~km}$. The region of interest shows moderate mass change signals. Panel (b) shows (red line) area averaged mass changes (GT), relative to 2003 levels, for the virginia region of interest. The NPP is plotted (black lines) to show possible trends in precipitation. This region's mass changes have strong correlations with precipitation.

Table 2. Azimuth angle (counter-clockwise from due east) and slope angle from the 168 scarps.

\begin{tabular}{|c|c|c|c|c|c|c|c|c|c|c|c|}
\hline \multicolumn{12}{|c|}{ Azimuth angle } \\
\hline $0-30$ & $30-60$ & $60-90$ & $90-120$ & $120-150$ & $150-180$ & $180-210$ & $210-240$ & $240-270$ & $270-300$ & $300-330$ & $330-360$ \\
\hline 27 & 8 & 9 & 14 & 9 & 8 & 7 & 3 & 6 & 8 & 7 & 11 \\
\hline \multicolumn{12}{|c|}{ Slope angle } \\
\hline & $0-18$ & & & $18-42$ & & & $42-66$ & & & $66-90$ & \\
\hline & 25 & & & 13 & & & 71 & & & 8 & \\
\hline
\end{tabular}


and less than 18 degrees for progressive bulking type slides/debris flows. The orientation preferences results from vegetation root preventative effects. In this moist climate zone, north-facing slopes tend to be grassy slopes.

Outside this domain, we have only $~ 30 \mathrm{~m}$ ASTER DEMs. Similar experiments identify the Black Mountain Valley as very unstable. The Black Mountain terrain forms a U-shaped semi-circle that opens to the northwest. This configuration, in addition to the orographic effects on precipitation, also favors surface runoff confluence and the collection of debris and granular sliding material (Figure S1(a)). At present, the area is well covered by forest (by firs trees at higher elevation and Eastern Hemlock trees at lower elevation) and this is a stabilizing effect as only $<0.01 \%$ of the slope area is unstable at present under extreme precipitation, mostly northeast facing slopes. In the future, removal of these trees either by insect infestation or by deforestation associated with rapid population growth, may significantly increase the landslide threats. The Black Mountain type of landslides are common for progressive bulking type landslides. A configuration even more favorable for sliding is when such a geographical feature is further nested in a larger front range that also has strong orographic enhancement to regional precipitation.

\subsection{Future Similar Landslide Events}

The Nelson County landslides were preceded by an extreme precipitation event that brought over $600 \mathrm{~mm}$ of rainfall within a narrow 8-hour time window, on August 19-20, 1969 (Figure 3). Both the model-determined precipitation intensity, which peaked at a rate of $1400 \mathrm{~mm} / \mathrm{hr}$ near $79^{\circ} \mathrm{W}, 37.78^{\circ} \mathrm{N}$ on the south-eastern slopes of the Blue Ridge Mountains, and a total rainfall of $\sim 900 \mathrm{~mm}$ in 24 hours, is the highest recorded in the region. Such a rainfall event has a 100-year return frequency under the present climatology, as determined by, for example, a generalized Pareto distribution (GPD) analysis [34] [35], inclusive of ongoing, significant climate change. Because the 1969 landslides produced significant life and economic loss, it is imperative to investigate the probability of future such events. Extreme precipitation is undoubtly the cause of the 1969 slides [7] [8] and also future such events. Climate warming thus is commonly seen as the likely major cause, by contributing to the severity of rainstorms (Chapter 14 in [1]). Alternatively, it is suggested (R. Pielke Sr., personal communication 2012) that a more important contributor is increased exposure, due to the expanding of population into naturally unstable areas, thereby disturbing the land cover and land use. This section dedicates to investigating future storm-triggered landslides.

Compared to the washout rate, the accumulation rate of granular sliding material is much slower. The availability of GM on the slopes is the first prerequisite for landslides. Because the chute system and underground crevasses are in a stable state, future storm-triggered landslides depend primarily on changes in extreme precipitation and the spatial coherence with GM's distribution patterns. How much sliding material can be mobilized on an unstable slope is co-determined by slope hydrology and precipitation characteristics (i.e., total amount as well as intensity distribution). For thoroughly fractured slopes, how much rainfall is infiltrated or drained into the ground is a key parameter for estimating the landslide magnitude [6]. The weight of rainfall is negligible in aiding the driving stress. However, if it can be effectively channeled into the interface between non-fractured bedrock and the overlaying GM lump, the effect on reducing the maximum resistive stress is significant. In addition, the concentrated water column inside the crevasses exerts a horizontally directed differential pore pressure, aiding the driving stress in overcoming the resistive stresses. Once the driving stress and the hydrostatic differential pore pressure together exceed the already reduced (by drainage lubrication) maximum available resistive stress, the entire layer is set into motion, even through most soil inside this layer still is dry. This exactly is the case of intense rainfall bursts, when there is insufficient time to infiltrate. The surface runoff, once enters crevasses, percolates to greater depths, creating a shear zone much deeper than uniform wetting can reach. The landslide magnitude thus is much larger for the intense storm case. In contrast, if the precipitation is retained entirely in the upper shallow layer and does not discharge into a deeper layer, only a very shallow layer is mobilized and this layer, by entraining drier material, quickly loses its fluidity and could stop mid-slope (could become fuel for following more intense rainfall) . Thus, any future changes in precipitation morphology and structure characteristics can have direct effects on the impact of storm-triggered landslides. This especially is true for graded slopes (those extended slopes as illustrated in Figure S1(b)). There also are also examples in which the state of the medium and the following severe rainfall intensity maximizes the sliding material gain (Figure S1).

To estimate possible changes in future extreme precipitation events, WRF is run with thermodynamic changes 
computed from a small 12-member IPCC GCM ensemble output, under the A1B emission scenario. The resulting simulation is a replication of a highly similar synoptic pattern to that of the control simulation, but within a projected future thermodynamic environment. Over the region of interest, the increased atmospheric water vapor levels, present as a direct thermodynamic consequence of warming, or a robust water vapor increase that is consistent with the Clausius-Clapeyron relationship, holds [36]-[38]. In addition, precipitation in the Appalachians also is strongly influenced by orographic effects, which was the case for the precipitation pattern from Camille 1969.

Figure 6 shows the resulting precipitation changes. Figure 6a is the WRF simulated Camille-like extreme precipitation event that caused total precipitation over Domain 3, but under a warming climate, the SRES A1B scenario in the 2060-80 timeframe. Compared with the actual Camille event of 1969, future such events are expected to have similar spatial patterns (c.f. Figure 3 and Figure 6(a)). Compared to the control run (Figure 3, under current climate), the spatial maximum value increased from $850 \mathrm{~mm}$ to $900 \mathrm{~mm}$. The grid point that receives this maximum rainfall amount does not always correspond to the same geographic location. Also, the increase in precipitation amount does not occur throughout the domain, and there are locations receive decreased rainfall as the climate warms (blue color shades in Figure 6(b)). The time series of accumulated total precipitation amount (in $109 \mathrm{~m}^{3}$, figure not shown) in Domain 5 indicates that the total precipitation does not increase significantly (less than 2\%). At the time of slope liquefaction, the difference in the total amount of rainfall in the simulation domain still is insignificant. Zooming into the slope of interest, however, reveals that the precipitation doubles, reaching $\sim 200 \mathrm{~mm}$ in the first hour. Compared with the control case, the distribution is more concentrated and shifted westward. The cluster center of future landslide scarps also shifts northwestward accordingly by about $30 \mathrm{~km}$. Thus, a warmer climate might signify a more spatially concentrated rainfall distribution with important landslide consequences over this region.

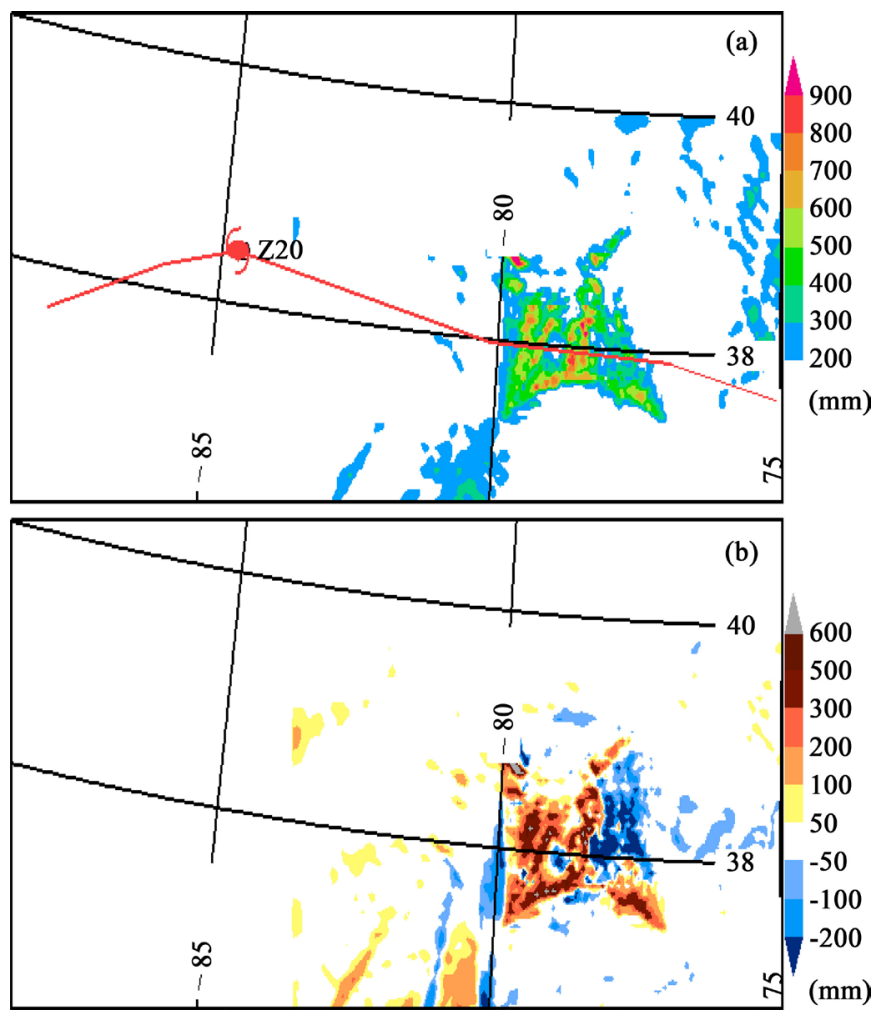

Figure 6. WRF simulated total precipitation over Domain 3 under a warming climate scenario (Panel (a), SRES A1B scenario) from a Hurricane Camille (1969)-like extreme precipitation event. Panel (b) is the differences between SRES A1B and current climate (Figure 3, Control). Comparison of (a) with Figure 3 indicates that the maximum value has increased from $850 \mathrm{~mm}$ to $900 \mathrm{~mm}$. However, Panel (b) indicates that the increase does not occur over the entire domain, as there are locations that received less rainfall. Compared with the Control run, the rainfall distribution is more concentrated and has shifted westward. 
The above results are in general agreement with the hypothesis of [39] regarding the climate response of extreme precipitation to increased air temperature resulting from increased atmospheric concentration of greenhouse gases. Whereas frontal passages are regular events, hurricanes are more irregular (with larger annual variability) and bring significant moisture into the region of interest. Extreme precipitation events over the Appalachians are frequently affected by TC remnants (from the north Atlantic TC Basin, Figure 7). It is notable that TC remnants, on the one hand, enhance instability by moistening the low level and, on the other hand, the cyclonic vorticity input to the upper level circulation (also is a lifting mechanism contributing to slantwise instability). In Figure 7, tracks of seventeen severe (Category 3 and above in the Saffir-Simpson wind-based scales) hurricanes, which brought extreme precipitation over the region of interest, defined by a $3 \times 3$ degree black box centered at Neson County, Virginia, since the passage of Camille in 1969 (i.e., for the period 1969-2012), are plotted. They generally follow three paths: western paths such as TC Ivan (2004); central paths (TC David 1979); and eastern paths (TC Floyd 1999). Except for Camille 1969 and Eloise 1975, all 15 remaining hurricanes occurred during the satellite era and the International Best Track Archive for Climate Stewardship (IBTrACS, http://www.ncdc.noaa.gov/oa/ibtracs/) data are reliable. To estimate future changes in the Atlantic basin hurricane activity, especially tracks and intensity, a vortex-tracking scheme 15 is used to identify TCs from the climate model simulated atmospheric fields. As the climate warms, the frequency of hurricane occurrence does not vary much but the intensity increases systematically with time. Under the current climate, it is very rare that two hurricanes occur simultaneously and travel north to affect the region of interest. Under a future warming climate, the changes are such that the trailing vortex of the major hurricane also can develop into a TC. The major TC takes the western route and the secondary one takes the eastern route and they head north simultaneously. This situation causes very strong precipitation and the resultant landslides also are of larger scale. Although the overall TCs do not have significant increase in occurrence frequency, it is found that the 'western path' category has a significant increase, especially after 2040 when approximately every five years such a TC will occur once. This primarily is caused by the expansion of the subtropical high.

Table 3 lists all the potential landslide scarps identified by SEGMENT-Landslide under a similar precipitation scenario as Camille 1969, but occurring in the 2060-80 time period. These locations have thus far not recorded storm-triggered landslides, but this study suggests that they should be tagged for future attention. Among

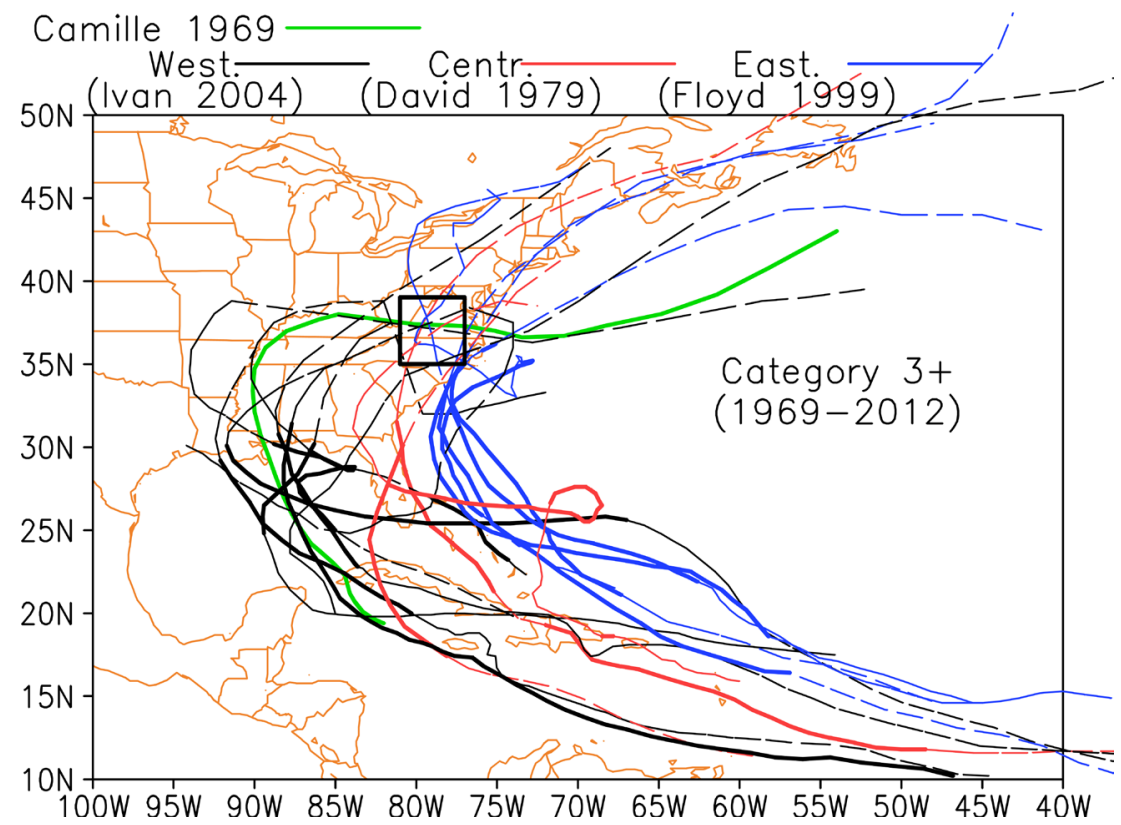

Figure 7. In addition to the warm conveyor belt mechanism, tropical cyclones are major contributors to extreme precipitation over the Appalachians. seventeen severe (category 3 and above) hurricanes have affected the region of interest since Camille, over the period 1969-2012. they follow three general paths: a western path such as Ivan (2004); a central path (David 1979); and an eastern path (Floyd 1999). The region of interest is defined by the 3 degree x3 degree black box centered on nelson county, Virginia. Except for Camille and Eloise (1975), all remaining 15 hurricanes occurred during the satellite era, and the available Ibtracs data are regarded as reliable. 
Table 3. The most endangered locations in the Appalachians during the 2060-80 timeframe. "S" means "salamander habitats”.

\begin{tabular}{|c|c|c|c|}
\hline lat & Lon & lat & Lon \\
\hline 36.925 & $-80.176(\mathrm{~S})$ & 37.85 & -81.87 \\
\hline 36.82 & $-80.31(\mathrm{~S})$ & 36.12 & -83.16 \\
\hline 38.455 & -78.437 & 36.08 & -83.07 (S) \\
\hline 38.45 & -78.44 & 35.4 & -80.0 \\
\hline 38.6 & -78.34 & 35.998 & -82.689 \\
\hline 38.228757 & $-78.693(\mathrm{~S})$ & 36.01 & -82.676 \\
\hline 38.314 & $-78.58(\mathrm{~S})$ & 35.96 & -82.657 \\
\hline 37.933 & -78.92 & 35.928 & -82.622 \\
\hline 37.74 & -79.14 & 35.6272 & $-82.25(\mathrm{~S})$ \\
\hline 37.84 & -79.0 & 35.625 & -84.14 \\
\hline 37.677 & -79.588 & 36.382 & -81.945 \\
\hline 37.62 & -79.64 & 38.782 & $-79.297(\mathrm{~S})$ \\
\hline 37.37 & -80.2 & 38.12 & -76.79 \\
\hline 37.62 & -80.01 & 39.10 & -84.822 \\
\hline 37.61 & -80.0 & 40.387 & -79.756 \\
\hline 38.44 & -78.35 (S) & 37.83 & -79.0 \\
\hline 38.42 & -78.36 & 37.8 & -78.9 \\
\hline 38.46 & -78.44 & 37.85 & -78.98 \\
\hline 38.5 & -78.35 & 37.845 & -78.97 \\
\hline 38.05 & -81.96 & 37.74 & -79.14 \\
\hline 38.08 & -81.98 & 37.83 & -79.55 \\
\hline 37.76 & -81.736 & 37.38 & -80.17 \\
\hline 37.42 & -80.22 & 37.48 & -80.13 \\
\hline 37.35 & -80.4 & 38.30 & -78.70 \\
\hline 38.81 & $-78.5(\mathrm{~S})$ & 38.91 & $-78.37(\mathrm{~S})$ \\
\hline 37.3 & -80.79 & 37.4 & $-80.48(\mathrm{~S})$ \\
\hline
\end{tabular}

these listed scarps, the valley near Shenandoah National Park $\left(38.3^{\circ} \mathrm{N}, 78.7^{\circ} \mathrm{W}\right)$ has perfect condition for storm-triggered landslides. Eight locales listed in the table collocate with natural habitats of the salamanders (those labeled with "S" in Table 3). Future landslide at these locations may have substantial effects on the adaptation of some endemic spices.

\section{Discussion}

The flash floods and landslides of the Appalachian hills during extreme precipitation events represent a significant threat to societal economic and social wellbeing. The destruction wrought by the 1969 Hurricane Camille is such an example. This study explores how landslides like that from Camille occurred and how future such events act as a threat accelerant to an already warming climate.

A case study of the August 1969 Hurricane Camille was carried out using the WRF simulated weather conditions. The event was a rare case of extreme precipitation showing that the entrainment of the water vapor remnants from a hurricane by mid-latitude system can be a cause of extreme precipitation. The Camille event occurred in the pre-satellite era and the simulated rainfall can only be verified with local witness accounts, media reports, indirect observations and the extremely fast increasing water levels in the creeks. The model simulated dynamic and thermodynamic features, however, are convincing and forms the basis for a series of experiments on climate sensitivity using the hypothesis of [11]. The experiments conducted with the WRF model suggest that this type of highly localized, heavy rain, as a result of an interaction of synoptic-scale weather systems with the mesoscale TC and topographical features, will be enhanced in magnitude in a warmer climate.

Because the well-developed chutes and gullies in the Blue Ridge and Appalachian Mountains, storm-triggered landslides can take the form of progressive bulking or of deep-seated, large scale slope instability, depending on 
the morphology of extreme precipitation. Land cover plays an important preventative role for the progressive bulking form of landslides. Very large drainage/percolation events could render the protective roots ineffective. This also explains why, although the slopes in general are randomly oriented, the unstable slopes tend to have a north facing component for the northern portion of the Appalachians and also tend to have a southerly component for the Black Mountains and the hills within Macon County. In a future warmer climate, extreme precipitation events tend to have larger magnitudes and might also occur more frequently. As a result, more frequent occurrence of storm-triggered landslides can be expected. The cluster center of the landslide scarps is found to shift westward, primarily as a result of the shift of the hurricane storm tracks. As karst landform is common over the region, even neighborhoods outside historical or geological river channels are no longer safe. Reducing global-wide greenhouse gases emission is an approach generally accepted as the most likely approach to reducing the occurrence of such disasters.

\section{Acknowledgements}

We thank Drs. Ming Yi (NCAR) and Xinyi Shen (OU) for technical assistance in processing the DEMs. Drs. Chris Harris (UWA) and Guoping Zhang (U. Macquire) assisted with utilization of the HPC facility at iVEC.

\section{References}

[1] IPCC, AR5 (2013) Climate Change 2013: The Physical Science Basis. Contribution of Working Group I to the Fifth Assessment Report of the Intergovernmental Panel on Climate Change. https://www.ipcc-wg1.unibe.ch/

[2] Ren, D., Leslie, L. and Karoly, D. (2008) Mudslide Risk Analysis Using a New Constitutive Relationship for Granular Flow. Earth Interactions, 12, 1-16. http://dx.doi.org/10.1175/2007EI237.1

[3] Ren, D., Wang, J., Fu, R., Karoly, D., Hong, Y., Leslie, L., Fu, C. and Huang, G. (2009) Mudslide Caused Ecosystem Degradation Following the Wenchuan Earthquake 2008. Geophysical Research Letters, 36, Article ID: L05401. http://dx.doi.org/10.1029/2008GL036702

[4] Ren, D., Leslie, L., Fu, R. and Dickinson, R. (2011) Predicting Storm-Triggered Landslides and Ecological Consequences. Bulletin of the American Meteorological Society, 92, 129-139. http://dx.doi.org/10.1175/2010BAMS3017.1

[5] Ren, D. (2014) Storm-Triggered Landslides in Warmer Climates. Springer-Verlag, Berlin.

[6] Ren, D. (2014) The Devastating Zhouqu Storm-Triggered Debris Flow of August 2010: Likely Causes and Possible Trends in a Future Warming Climate. Journal of Geophysical Research, 119, 3643-3662. http://dx.doi.org/10.1002/2013jd020881

[7] Williams, G. and Guy, H. (1973) Erosional and Depositional Aspects of Hurricane Camille in Virginia, 1969. US Geological Survey Professional Paper 804, 80 p.

[8] Gryta, J.J. and Bartholomew, M. (1989) Factors Influencing the Distribution of Debris Avalanches Associated with the 1969 Hurricane Camille in Nelson County, Virginia. Geological Society of America Special Papers 236, 15-28. http://dx.doi.org/10.1130/spe236-p15

[9] Iverson, R. (1997) The Physics of Debris Flows. Review of Geophysics, 35, 245-296. http://dx.doi.org/10.1029/97RG00426

[10] Ren, D., Lynch, M., Leslie, L.M. and LeMarshall, J. (2014) Sensitivity of Tropical Cyclone Tracks and Intensity to Ocean Surface Temperature: Four Cases in Four Different Basins. Tellus A, 66, 24212. http://dx.doi.org/10.3402/tellusa.v66.24212

[11] Lackmann, G. (2013) The South-Central US Flood of May 2010, Present and Future. Journal of Climate, 26, 46884709. http://dx.doi.org/10.1175/JCLI-D-12-00392.1

[12] Trenberth, K. (1999) Conceptual Framework for Changes of Extremes of the Hydrological Cycle with Climate Change. Climatic Change, 42, 327-339. http://dx.doi.org/10.1023/A:1005488920935

[13] Vaidya, S. and Kulkarni, J. (2007) Simulation of Heavy Precipitation over Santacruz, Mumbai on 26 July 2005, Using Numerical Model. Meteorology and Atmospheric Physics, 98, 55-66. http://dx.doi.org/10.1007/s00703-006-0233-4

[14] Bassill, N. (2014) Accuracy of Early GFS and ECMWF Sandy (2012) Track Forecasts: Evidence for a Dependence on Cumulus Parameterization. GRL, 41, 3274-3281. http://dx.doi.org/10.1002/2014GL059839

[15] Ren, D. and Leslie, L.M. (2014) Changes in Tropical Cyclone Activities over Northwest Western Australia in the Past Fifty Years and a Perspective into Future Fifty Years. Earth Interactions, 19, 1-24. http://dx.doi.org/10.1175/EI-D-14-0006.1

[16] USGS 2004. http://srtm.usgs.gov. 
[17] Orlanski, I. (1982) Orographically Induced Vortex Centers. Proceedings of the First Sino-American Workshop on Mountain Meteorology, Beijing, 18-23 May 1982, 699 p.

[18] Hart, R. and Evans, J.L. (2001) A Climatology of Extratropical Transition of Atlantic Tropical Cyclones. Journal of Climate, 14, 546-564. http://dx.doi.org/10.1175/1520-0442(2001)014<0546:ACOTET>2.0.CO;2

[19] Rader, E.K. and Evans, N.H. (1993) Geologic Map of Virginia-Expanded Explanation. Virginia Division of Mineral Resources, Charlottesville, $80 \mathrm{p}$.

[20] Bloomer, R.O. and Werner, H.J. (1955) Geology of the Blue Ridge Region in Central Virginia. Geological Society of America Bulletin, 66, 579-606. http://dx.doi.org/10.1130/0016-7606(1955)66[579:GOTBRR]2.0.CO;2

[21] Famiglietti, J. and Rodell, M. (2013) Water in the Balance. Science, 340, 1300-1301. http://dx.doi.org/10.1126/science.1236460

[22] Scanlon, B.R., Faunt, C.C., Longuevergne, L., Reedy, R.C., Alley, W.M., McGuire, V.L. and McMahon, P.B. (2012) Groundwater Depletion and Sustainability of Irrigation in the US High Plains and Central Valley. Proceedings of the National Academy of Sciences of the United States of America, 109, 9320-9325. http://dx.doi.org/10.1073/pnas.1200311109

[23] Voss, K., Famiglietti, J., Lo, M., de Linage, C., Rodell, M. and Swenson, S. (2013) Groundwater Depletion in the Middle East from GRACE with Implications for Transboundary Water Management in the Tigris-Euphrates-Western Iran Region. Water Resources Research, 49, 904-914. http://dx.doi.org/10.1002/wrcr.20078

[24] Eswaran, H., Rice, T., Ahrens, R. and Stewart, B., Eds. (2002) Soil Classification: A Global Reference. CRC Press, Boca Raton.

[25] Buol, S., Southard, R., Graham, R. and McDabiel, P. (2003) Soil Genesis and Classification. 5th Edition, Iowa State University Press, Ames.

[26] ASTM (1985) Standard Test Method for Classification of Soils for Engineering Purposes. American Society for Testing and Materials, ASTM Designation D 2487-83, Annual Book of ASTM Standards, Section 4, Volume 04.08, 395408.

[27] Hogentogler, C. and Terzaghi, K. (1929) Interrelationship of Load, Road and Subgrade. Public Roads, 10, 37-64.

[28] Soil Survey Division Staff (1993) Soil Survey Manual. USDA Handbook No. 18, US Government Printing Office, Washington DC.

[29] Lawrence, D. and Slater, A. (2008) Incorporating Organic Soil into a Global Climate Model. Climate Dynamics, 30, 145-160. http://dx.doi.org/10.1007/s00382-007-0278-1

[30] Homer, C., Huang, C., Yang, L., Wylie, B. and Coan, M. (2004) Development of a 2001 National Landcover Database for the United States. Photogrammetric Engineering and Remote Sensing, 70, 829-840. http://dx.doi.org/10.14358/PERS.70.7.829

[31] Belward, A.S., Ed. (1996) The IGBP-DIS Global 1 km Land Cover Data Set "DISCOVER”: Proposal and Implementation Plans. Report WP No. 13, IGBP-DIS, Stockholm.

[32] Hansen, D. (2001) Defining Cooperative Geospatial Projects between Organizations. In: Hansen, D.T., Singhroy, V.H., Pierce, R.R. and Johnson, A.I., Eds., Spatial Methods for Solution of Environmental and Hydrologic Problems: Science, Policy, and Standardization, ASTM STP 1420, American Society for Testing and Materials, West Conshohocken.

[33] Zhao, M. and Running, S. (2010) Drought-Induced Reduction in Global Terrestrial Net Primary Production from 2000 through 2009. Science, 329, 940-943. http://dx.doi.org/10.1126/science.1192666

[34] Coles, S. (2001) An Introduction to Statistical Modeling of Extreme Values. Springer Series in Statistics, SpringerVerlag, London, 224. http://dx.doi.org/10.1007/978-1-4471-3675-0

[35] Balkema, A. and de Haan, L. (1974) Residual Lifetime at Great Age. Annals of Probability, 2, 792-804. http://dx.doi.org/10.1214/aop/1176996548

[36] Karl, T. and Knight, R. (1998) Secular Trends of Precipitation Amount, Frequency, and Intensity in the USA. Bulletin of the American Meteorological Society, 79, 231-241. http://dx.doi.org/10.1175/1520-0477(1998)079<0231:STOPAF>2.0.CO;2

[37] Semenov, V. and Bengtsson, L. (2002) Secular Trends in Daily Precipitation Characteristic Greenhouse Gas Simulation with a Coupled AOGCM. Climate Dynamics, 19, 123-140. http://dx.doi.org/10.1007/s00382-001-0218-4

[38] Groisman, P.Y., Knight, R.W., Easterling, D.R., Karl, T.R., Hegerl, G.C. and Razuvaev, V.N. (2005) Trends in Intense Precipitation in the Climate Record. Journal of Climate, 18, 1326-1350. http://dx.doi.org/10.1175/JCLI3339.1

[39] Allen, M.R. and Ingram, W.J. (2002) Constraints on Future Changes in Climate and the Hydrological Cycle. Nature, 419, 224-232. http://dx.doi.org/10.1038/nature01092

[40] Sidle, R. (1992) A Theoretical Model of the Effects of Timber Harvesting on Slope Stability. Water Resources Re- 
search, 28, 1897-1910. http://dx.doi.org/10.1029/92WR00804

[41] Timoshenko, S. and Gere, J. (1963) Theory of Elastic Stability. 2nd Edition, McGraw-Hill, New York.

[42] Townsend, F. and Gilbert, P. (1973) Tests to Measure Residual Strengths of Some Clay Shales. GeÂotechnique, 23, 267-271. http://dx.doi.org/10.1680/geot.1973.23.2.267

[43] Doswell III, C.A. (1987) The Distinction between Large-Scale and Mesoscale Contribution to Severe Convection: A Case Study Example. Weather and Forecasting, 2, 3-16. http://dx.doi.org/10.1175/1520-0434(1987)002<0003:TDBLSA>2.0.CO;2

[44] Groisman, P.Y., Knight, R.W. and Karl, T.R. (2012) Changes in Intense Precipitation over the Central United States. Journal of Hydrometeorology, 13, 47-66. http://dx.doi.org/10.1175/JHM-D-11-039.1

[45] Carlson, T., Benjamin, S., Forbes, G. and Li, Y. (1983) Elevated Mixed Layers in the Regional Severe Storm Environment: Conceptual Model and Case Studies. Monthly Weather Review, 111, 1453-1473. http://dx.doi.org/10.1175/1520-0493(1983)111<1453:EMLITR>2.0.CO;2 


\section{Appendix I}

The material involved in landslides is not a single solid type; rather, a multiple-body of countless degree of freedom is involved: a lump of granular material, with rocks at the coarse end of grain size and sandy loam soil at the fine end of grain size. Parameterizing the granular viscosity is critical for a dynamic landslide model. In SEGMENT-Landslide, the granular viscosity is parameterized as

$$
v=\left(\mu_{0}+\frac{\mu_{1}-\mu_{0}}{I_{0} / I+1}\right) \frac{S}{\left|\dot{\varepsilon}_{e}\right|}
$$

where $v$ is viscosity, $S$ is the spherical part of the stress tensor $\sigma, \mu_{0}$ and $\mu_{1}$ are the limiting values for the friction coefficient $\mu,\left|\dot{\varepsilon}_{e}\right|$ is the effective strain rate and $\left|\dot{\varepsilon}_{e}\right|=\left(0.5 \dot{\varepsilon}_{i j} \dot{\varepsilon}_{i j}\right)^{0.5}, I_{0}$ is a constant depending on the local slope of the footing bed as well as the material properties, and $I$ is inertial number defined as

$I=\left|\dot{\varepsilon}_{e}\right| d /\left(S / \rho_{s}\right)^{0.5}$, where $d$ is particle diameter and $\rho_{s}$ is the particle density. The soil moisture enhancement factor for viscosity is assumed to vary according a sigmoid curve formally as Equation (A1.9) of [40], but with the time decay term replaced by relative saturation. To fully understand the $S$ term, we would like to give a quick review of stress field inside granular material and the concept of "region of influence" in granular material (GM). Landslides involve weathered rock material generally termed granular material. Granular material is a multibody, loose assemblage of solid granules of the same chemical and physical properties as their non-fractured source material. Because of the increased degree of freedom, the inter-particle interactions, through collisions as well as interfacial actions, can manifest macroscopically as having fluidity while remaining solids individually. The mean free path (relative to average granule dimension), analogous to the Prandtl mixing length in fluid dynamics, is much smaller than for fluid molecules. Moreover, exchanging locations with neighboring particles requires an energy expense to overcome friction. This explains why shaking and adding interstitial fluids increase GM fluidity. The load of precipitation water is secondary compared to its effect on increasing the fluidity of granular sliding material (e.g., lubrication effect). This limited fluidity explains why a solid body placed on top of a GM bed finds an equilibrium position at any depth. There is no hydrostatic parallel inside GM's internal stress fields. The pressure field inside the GM is highly anisotropic. Relationships between stresses in different principal directions are known to be loosely confined by yielding criteria [41]. Although GMs are not true fluids, the resistance forces in separating the granules arise primarily from the gravity of the involved GM, whereas cohesive bonding is weak or non-existent.

All forms of rock, when unfractured, are stronger than surface sloping caused driving stress. In this sense, landslides involve weathered, granular materials. Figure S5 shows how a load/intruder on a bed of an idealized granular substance perturbs stress fields. Because of complex internal stress fields within the GM, resistive forces to the load cannot be estimated using the hydrostatic relationship. Suppose the iso-line touching the outer contour of the load has a curvature $r_{0}$, at its nadir. Away from the load, iso-lines become flatter and particles there less affected by the load. When the curvature is $r_{0} / e$, the oval surface of this iso-line defines the "influence/ mobilization domain” (ID) (the space inside this partial oval). Within the ID, granules experience different degrees of elastic compression. Suppose that the largest extra strain rate due to the load is $\varepsilon$, granules that experience strain rate greater than the e-fold value of $\varepsilon$ forms a more qualitative definition of ID. In Figure S5, owing to the concave configuration of the compressed granules, the vertical component of the compression is a source of lift. As the GM weight within the ID cannot translate directly to lift to balance the load weight, equilibrium is provided by shear stress (friction) and normal stress (granule compression). Perturbations from the load cannot be localized. Instead, all granules within the ID are mobilized and work in concert to resist the load. Another lift source is lateral frictional forces exerted on the load by surrounding granules, and may be dominant when the ID domain intercepts the container boundary.

Although the load can maintain the force-balance at arbitrary depths exceeding the minimum depth, motion within the GM involves energy loss through irreversible heat dissipation. The rate of energy loss is nonlinearly proportional to ID volume, motion speed, and granular viscosity. The seemingly simple process of slowly placing a load on GM actually involves the gradual increasing of the ID domain, transforming potential energy into heat, and generating lift (Figure S5). Consequently, the minimum depth at which the vegetation roots remain depends on the plant weight and footprint. Theoretically, the root can be at any depth greater than the minimum 
depth. However, in reality, root depth distribution is seldom controlled by this requirement. Instead, many distribution patterns are explainable by optimal usage of water and nutrients. For landslide applications, the load/intruder's ID is parallel to the yielding surface. For sandy soil, adding water can significantly reduce the ID size. Because the strength of the GM is controlled by the magnitude of rainfall and its distribution, which in turn is largely controlled by the chute density and distribution, the typical scarp scoured during slope failure (e.g., for the Blue Ridge slopes, under Hurricane Camille's estimated extreme precipitation of $\sim 600 \mathrm{~mm}$ within a 6-hr window, is about $120 \mathrm{~m}$ long, $12 \mathrm{~m}$ wide and $0.66 \mathrm{~m}$ deep, on average.

Using this concept, scarp/chute shape and size for the non-uniform composition case can also be explained. In fact, for the Blue Ridge Mountain region, it is the rock fabrics that influenced the preferred chute orientations in most rock types. Thus, a detailed survey of the regional foliation is also an important step in setting up the numerical landslide model. For SEGMENT-landslide, the rocks with biotite and amphihole foliation are assigned an enhancing factor in the viscosity parameterization.

Under the unique processes of Earth environments the mechanical strength of granular material is further altered by vegetation roots (fortification effects), or tunnels made by subterranean animals (weakening effects). For granular material resting on vegetated slopes, the cohesion provided by the roots is implemented in the full internal stresses $\sigma^{\prime} s$. The root mechanical properties are prescribed according to the vegetation types over the region of interest. As a loading on granular slope material, slope surface vegetation, especially forests, has multi-facet effects on slope stability. The canopy can intercept precipitation (the maximum capacity depends on growth stage and vegetation density, and varies seasonally) and reduce the surface infiltration and runoff. In this sense, it is a stabilization/protective factor. Also, the roots distributed inside the soil act analogous to iron reinforcement of concrete. However, if precipitation amount is too large or the confluence upslope runoff is so large and saturates the granular material to a depth exceeding the root depth, the reinforcement effect may diminish and the trees become debris and join the sliding granular material. In addition, the cavity surrounding roots also provides a convenient channel for percolation of surface runoff (Figure S1 of [6]).

Mountain sloping is the result of two contesting process: advection transport (cutting) and diffusive smoothing (healing). As a result, the slopes are generally steep at the top and gradually get gentler near the toe. Sliding

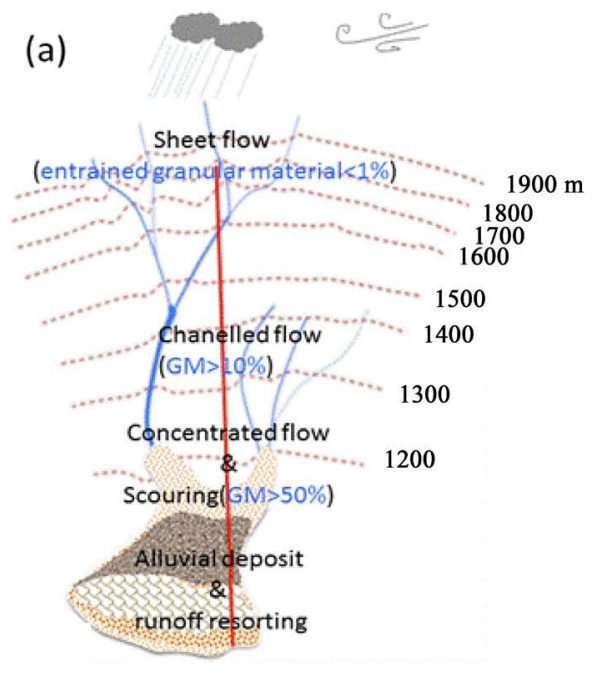

(b)

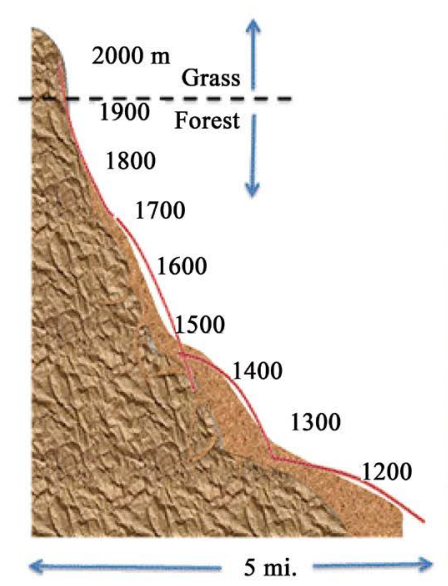

(c)

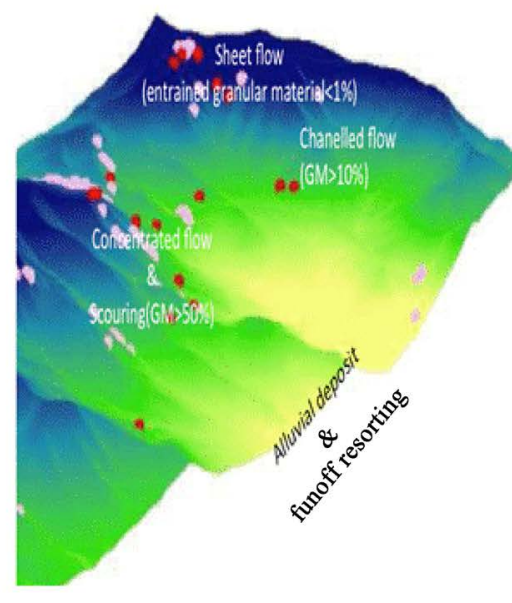

Figure S1. A characteristic storm-triggered landslide (a debris flow). Left panel (a) is a plane view of the entire (solid material) collection basin. The elevation divisions are only for reference in the Black Mountain Range. The section with concentrated solid material creeping is only a small portion of the entire area. This means of mass redistribution is referred to as "progressive bulking” [9]. Center panel (b) is a cross-sectional view along the red line (on panel (a)), showing graded slope feature: upper segment is steeper than the toe section. Depending on the orientation (azimuth) of the slope and climate zone, the forest line may fluctuate. This is based on the U-shaped semi-circle defined by the Black Mountain, NC (panel (c)). For non-uniform graded slopes, at medium rainfall rates, sliding material usually cannot slide all the way to the toe, and stops mid-slope. The subsequent, more intense rainfall event then is capable of sending the material all the way to the toe, while entraining along the way at a significantly larger rate, because the entrainment process is non-linearly related to the instantaneous amount of sliding material. 
(a)

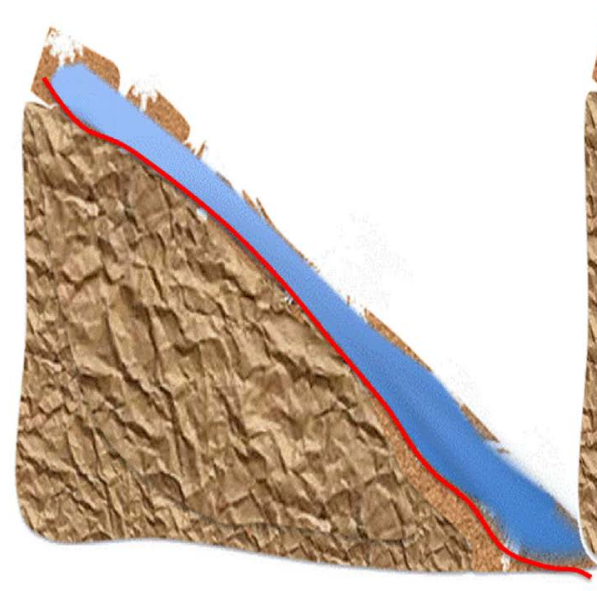

(b)

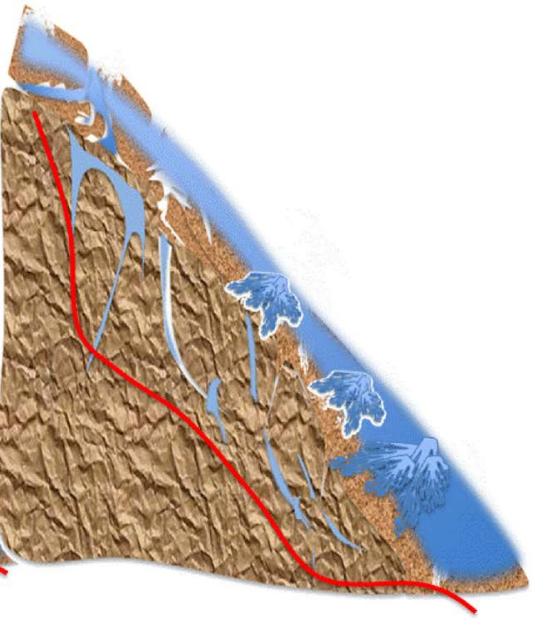

Figure S2. Effects of bedrock cracking. Bedrock crevasses under the rhizosphere are usually filled with fine weathered soil (b). Cyan indicates wet soil and accumulated groundwater. Panel (a) illustrates a vertical cross-section of a slope, with least fractured bedrock. The shear surface (red thick line) is just within the rhizosphere parallel to the saturation front. Panel (b) illustrates the situation with same rainfall morphology but the region is underlain by a fractured/cracked bedrock. Because of the presence of cracks, the rainfall can saturate to a much deeper depth so the shear surface occurs at a much deeper level than in case (a).

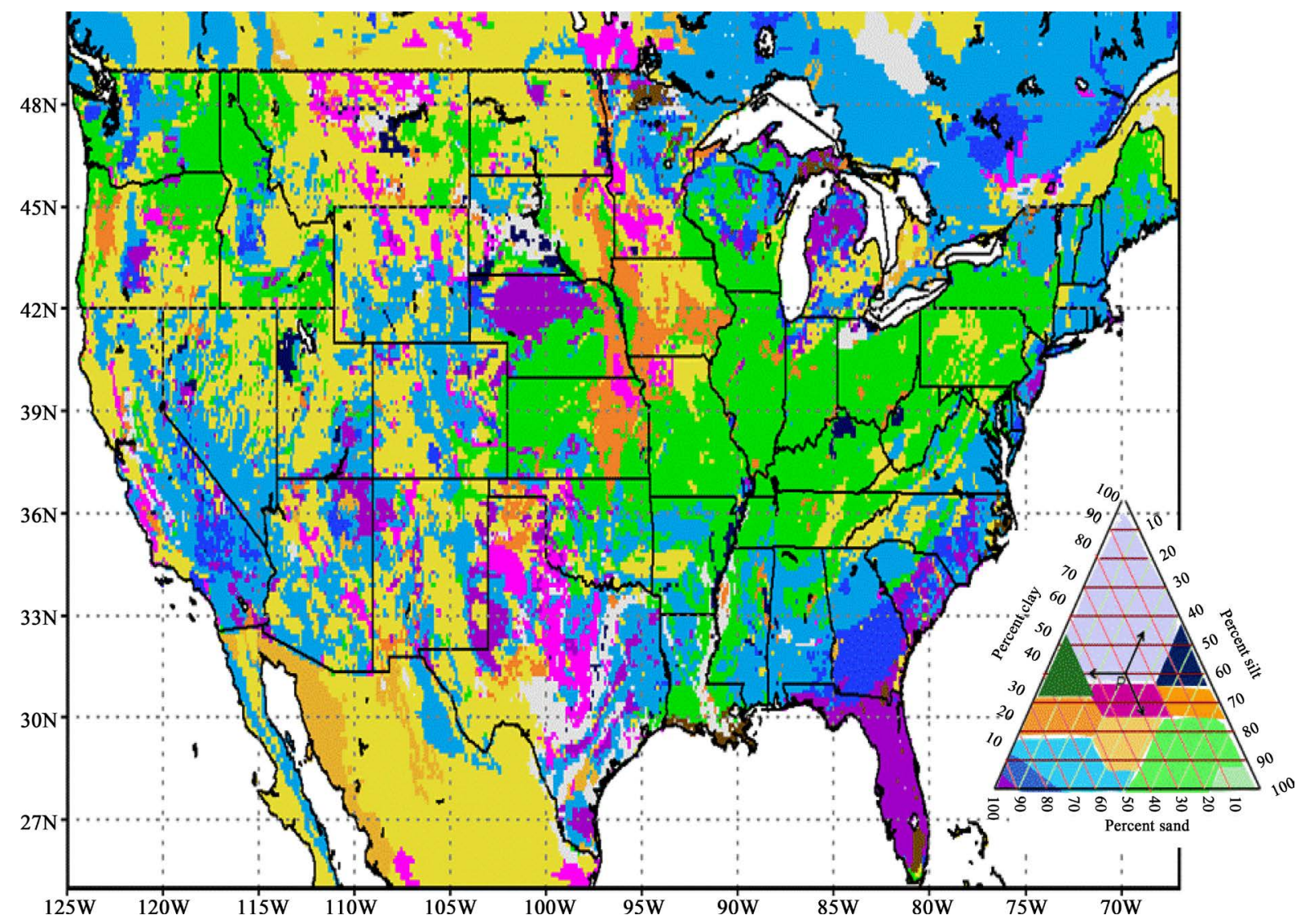

Figure S3. The predominant surface soil texture obtained from STATSGO. The inset is a ternary diagram showing the soil classification as relative percentages of sand, silt, and clay in the basic textural classes. For any point on this phase diagram, the percentages are shown in the three directions (120 degrees in between any two directions), adding to unity. The STATSGO classification includes soil stratigraphy information, which is not shown here as this is just the surface layer. 


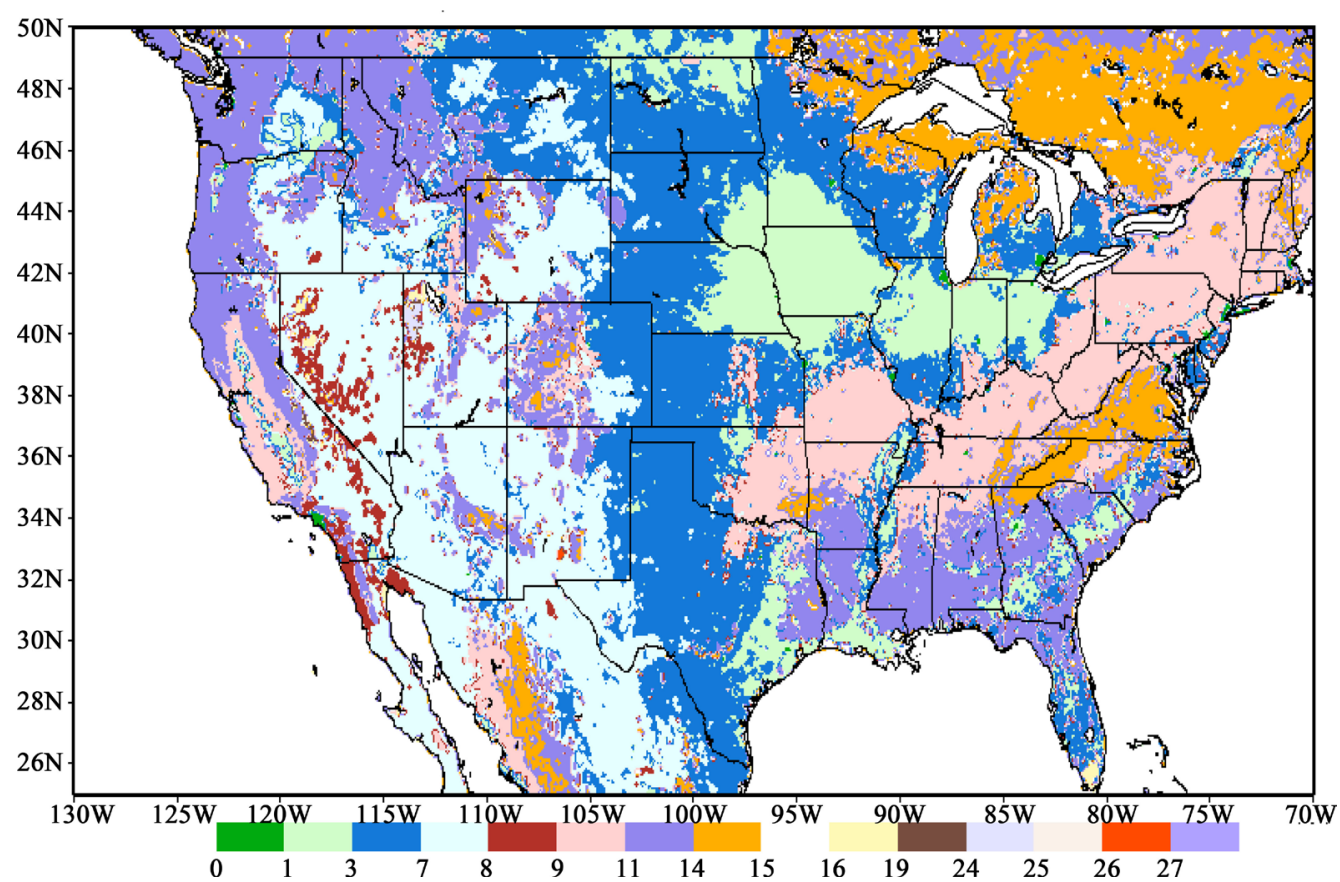

1:Urban Impenetrable surfaces; 2: Dryland Cropland and Pasture; 3; Irrigated Cropland and Pasture; 4: Mixed Dryland/Irrigated Cropland; 5:Cropland/Grassland Mosaic; 6:Cropland/Woodland; 7:Grassland; 8: Shrubland; 9: Mixed Shrubland/Grassland; 10: Savanna; 11: Deciduous Broadleaf; 12:Deciduous Needle-leaf; 13:Evergreen Broadleaf; 14: Evergreen Needle-leaf; 15: Mixed Forest; 16: Water Surface; 17: Herbaceous Tundra; 18: Wooded Wetland; 19: Barren; 20: Herbaceous Tundra; 21: Wooded Tundra; 22: Mixed tundra; 23: Bareground Tundra; 24: Glaciated; 25: Playa; 26: Lava; 27 White Sand

Figure S4. The USGS/EROS $1 \mathrm{~km}$ vegetation type. AVHRR products [42].

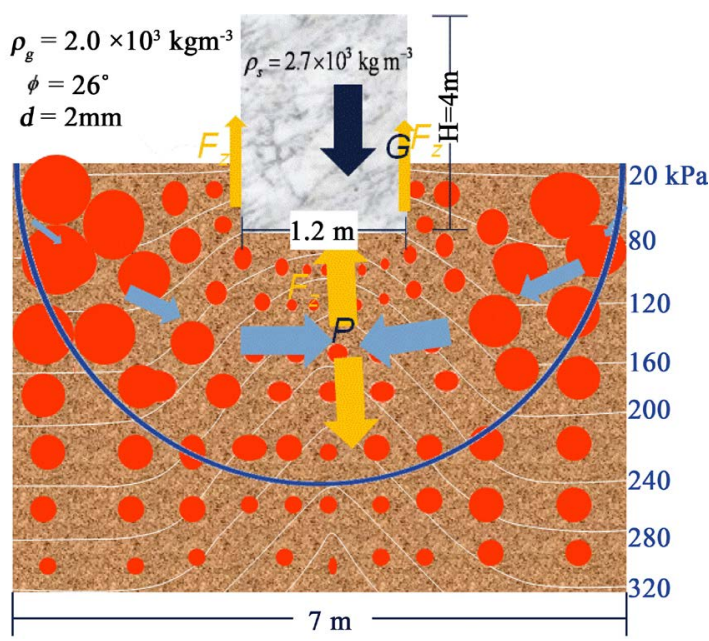

Figure S5. Granular responses to loading, showing "lift” generation, minimum intruder depth, and domain of influence (ID, the region confined by the bold blue curve). Panel (a) is a cross-section of a load placed on GM. Contour lines are vertical components of compressive stress within the GM. Red blobs indicate elastic granules of identical size when not compressed. Bold arrows are forces; black arrows are gravity, yellow arrows are lifts, and cyan arrows are confining stresses within the ID. Red bubbles of different sizes show degrees of compression (exaggerated). When the load is moving inside the GM, its ID follows, as explained in the text. Internal granular stress is highly anisotropic with no "hydrostatic" relationship. Doubling the weight of the load does not double the minimum set-in depth. Vertical pressure is not necessarily greater than the horizontal component, especially for large repose angle $\phi$ or if the ID intercepts the lateral container boundaries. Pressure components in different directions are only weakly constrained by yielding criteria. The lack of hydrostatic pressure in granular rocks is best manifested in the sensitivity of slide to pore pressure. The vertical pressure may be huge but the horizontal stresses are so small that the percolated rainfall into the crevasses caused excessive pore water pressure can "push" the outward neighboring rock into motion! Soil and vegetation effects on slope stability are parameterized in SEGMENT-Landslide. 
material from upper slope may not descend to the toe, but instead stop at mid-slope. This has important implications for GM distribution along slopes.

Finally, a more favorable condition for progressive bulking landslides is concave sloping, with a large collecting area for debris and surface runoff (e.g., the Black Mountain configuration; Figure S1(a), Figure S1(c)). Surface runoff concentrated into creeks has more power to erode the creek banks, and failure of creek banks is a major contributor of sliding material volume.

Thus, landslides occupy a unique nexus in the geomorphology research by providing the tectonic-climatetopography-erosion-river incision interlinks, unifying several disciplines on subjects ranging on many different spatial and temporal scales. Complex landforms are the products of deep Earth processes involving mantle convection and plumes producing plate tectonics. Thus the major factors in landslide occurrence are orogeny and epeirogeny, as well as the surface processes of soil formation, denudation, and sedimentation, influenced by seismicity, climate change (primarily changes in extreme precipitation), and land cover change, with a recent (on geological scale) significant role for human agency.

\section{Appendix II. Extreme Precipitation under a Future Climate Scenario}

Latent heat release and the accompanying precipitation is a link of the global energy and hydrological cycle. Extreme precipitation should be viewed in this context. During extreme precipitation the moisture source, especially for locations over land, are usually non-local and are transported remotely, for example by low level jets (LLJs). In line with the Doswell's [43] triad of ingredients for severe convection, when several factors are working in tandem in low level water vapor build-up (e.g., favorable vapor condition during monsoon season, stronger LLJs, TC remnants), in providing lifting mechanisms, including orographic lifting, passage of low pressure systems, favorable LLJs and high level jet configurations, cyclonic vorticity from TC remnants, differential heating due to land cover contrast, repeated lifting mechanisms, and slowing down of the evolution of the precipitation system (e.g., establishing an interlocking pattern that makes the precipitation system quasi-stationary), extreme precipitation may occur.

In reality, extreme precipitation is caused either by blocking systems, including blocking highs and cut-off lows, or unfortunate combination of several rainmakers. To produce extreme precipitation, the blocking high and cut-off low must evolve more slowly than usual. We have the following two diagnostic measures to quantify the blocking: an extreme precipitation index; and a Q-vector component perpendicular to the isentropes.

The canonical $\omega$-equation reads:

$$
\left(\nabla_{p}^{2}+\frac{f_{0}^{2}}{\sigma} \frac{\partial^{2}}{\partial p^{2}}\right) \omega=-2 \nabla_{p} \cdot \mathbf{Q}
$$

Following a partitioning methodology of $Q$ into $Q_{s}$ and $Q_{n}$, which are the along- and across-isentrope components of the Q-vector, when $\nabla_{p} \cdot \boldsymbol{Q}_{s}<0$, there is synoptic scale forcing for ascent. Similarly, $\nabla_{p} \cdot \boldsymbol{Q}_{n}<0$ represents mesoscale forcing for ascent. Through this means of decomposition, there is a closer examination of the extreme (top 10\% heavy) precipitation dynamics. Climate warming of this expression lies with 1) more water vapor in the air, more severe precipitation and, more importantly, 2) the most effective situation is with both greater ascent (in a less stable air mass, as implicit in $\omega$ ) and a warmer airmass, as represented in the following extreme precipitation index (EPI):

$$
P=-\frac{1}{g} \int \omega\left(\frac{\mathrm{d} r_{s}}{\mathrm{~d} p}\right)_{m a} \mathrm{~d} p
$$

where $P$ is precipitation rate, $g$ is gravity acceleration, $\mathrm{d} r_{s} / \mathrm{d} p$ is the change in saturated mixing ratio with height along the moist adiabat (subscript $m a$ ), and $\omega$ is as in (A2.1) vertical ascent motion. This approach is in accordance with [44]. Equation (A2.2) also explains the fact that the more concentrated the warm moist air concentrated to the surface, the stronger the precipitation efficiency. For example, the "explosive" storms over the US central plains: warm moist air from the Gulf of Mexico undercuts potentially warmer, but drier air (originated from the Mexican Plateau), a common feature for regions with arid plateaus adjacent to moist lowlands [45]. The overrunning warm plume from the elevated terrain creates a lid, or capping inversion, that temporarily suppress convection, allowing conditional instability to build up, only to be released violently near the lateral edge of the elevated mixed layer. Reflected in Equation (A2.2), this produces a larger integrated value of 


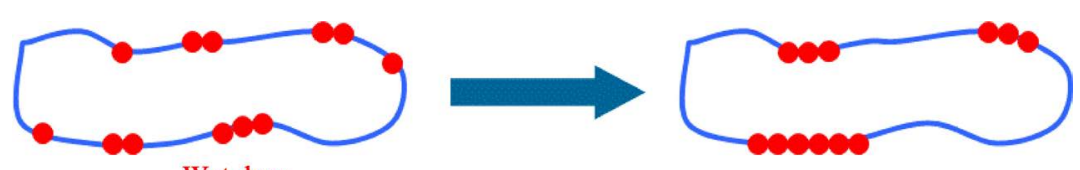

Wet days

Figure S6. Red beads indicate precipitation events, and the blue segments indicate 'dry periods' in between. The left side (of the blue arrow) indicates the present climate and the right side is a future warmer climate (P. Groisman (personal communication, 2013). For more extreme events the beads are clustered together. If the number is $>3$ the event is extreme. It increases from 1 in the present climate to 3 in a warmer climate, but are separated further apart in time (implying more extended droughts). This drought-extreme precipitation bi-polar pattern favors more severe landslides.

$\mathrm{d} r_{s} / \mathrm{d} p$, or higher precipitation efficiency.

All else being equal, the absolute amount of vapor is proportional to total precipitation. Thus a deeper moist lower level produces higher precipitation amounts. This partially explains the correlation of El Nino events with Southern California Rainfall. As global water vapor is controlled by air temperature an excessive amount in this region means less in other regions. Similarly, climate warming's effect on extreme precipitation can be explained in this framework as an enhanced $r_{s}$ and a deeper moist lower level. Several factors can work in tandem to enhance the lifting (vertical motion $w$ ). In the case of July 25, 2005, which recorded extreme monsoon precipitation over Mumbai, India, the moisture-laden Somali Jet was orographically lifted when meeting the Western Ghats of India. At the same time, a northwestward moving low pressure system from the Bay of Bengal was passing over Mumbai. It was further aided from the differential heating from very different lower boundary conditions; the ocean, metropolitan Mumbai, and the sloping Western Ghats enhanced the precipitation efficiency.

To produce extreme precipitation, in addition to Doswell's triad of ingredients, there needs to be an established interlocking pattern that makes the precipitation system nearly stationary (e.g., cold and dry downdraft was forced to be discharged/exhausted out in a direction counter the inflowing air), or makes the lifting mechanism follow a repeated pattern (e.g., a series of short wave length waves in the upper level, e.g., the situation of leeward of Plateaus, at a distance from the Front Ranges). In the present period of salient climate change, the Intergovernmental Panel on Climate Change (Chapter 7 in WG1's report [1]) uses very strong/affirmative worded language about the increase in extreme precipitation events. The consensus of extreme precipitation among researchers is illustrated in Figure S6. 